\title{
¿ES POSIBLE LA JUSTICIA RESTAURATIVA EN LA DELINCUENCIA DE CUELLO BLANCO?*
}

\author{
María Jesús Guardiola Lago**
}

Resumen: En este trabajo se exploran las posibilidades de llevar a cabo iniciativas restaurativas en el ámbito de la delincuencia de cuello blanco. La autora identifica tres aproximaciones en la evolución del concepto de justicia restaurativa y valora, en cada una de ellas, la viabilidad de que los delitos socioeconómicos se puedan incluir en las mismas. Se analiza desde el fundamento y objetivos de la justicia restaurativa en los delitos de cuello blanco hasta los procesos restaurativos que resultarían más adecuados, teniendo en cuenta que los conceptos de daño, víctima, ofensor y comunidad deben ser adaptados para responder restaurativamente a este tipo de criminalidad. La necesaria complementariedad de la justicia restaurativa con el sistema de justicia penal puede ser una

Recibido: marzo 2020. Aceptado: julio 2020

* Este trabajo se enmarca en el desarrollo del Proyecto I+D+i "Reparación, Justicia Restaurativa y mediación en la delincuencia socioeconómica" (DER2017-84088-R).

** Prof. Lectora (Serra Hunter) de Derecho penal.

Facultad de Derecho. Universidad Autónoma de Barcelona. Edificio B. Calle de la Fortuna, 08193. Bellaterra (Cerdanyola del Vallès). Barcelona. mariajesus.guardiola@uab.cat 
oportunidad para repensar instituciones penales desde una perspectiva restaurativa. Sin embargo, un concepto amplio de justicia restaurativa corre el riesgo de desdibujar sus contornos y de que ésta quede absorbida por el sistema de justicia penal.

Palabras clave: Justicia restaurativa, conferencing, delincuencia de cuello blanco, víctimas colectivas, daño social.

\section{IS RESTORATIVE JUSTICE A VIABLE OPTION FOR WHITE-COLLAR CRIMES?}

Summary: This paper explores the possibility of applying restorative justice to white collar crime. Three approaches in the evolution of the concept of restorative justice are identified and evaluated, and the suitability of one of them for socio-economic crimes is verified. The author specifically analyzes the functioning of restorative justice principles and objectives for socio-economic crimes, and examines which restorative processes would be most appropriate, considering that concepts like harm, victim, offender and community must be adapted to address this type of crime in a restorative way. Improving restorative justice within the criminal justice system can give the opportunity to rethink penal institutions from a restorative perspective. However, relying on a too broad concept could result in restorative justice losing its distinctiveness and being absorbed in the criminal justice system.

Key words: Restorative justice, conferencing, white collar crime, collective victims, social harm.

\section{Introducción}

Resulta muy sugerente analizar las posibilidades de aplicar procesos restaurativos a la delincuencia de cuello blanco. En primer lugar, porque los dos términos de comparación poseen contornos imprecisos y se encuentran en constante evolución. Así, pese a que existen adaptaciones dogmáticas para responder a este tipo de delincuencia en el ámbito jurídico-penal ${ }^{1}$, y diver-

1 Hasta el punto de que existe manualística especializada en la parte general del Derecho penal económico. Vid. MARTÍNEZ-BUJAN PÉREZ, C.: 
sas publicaciones en el ámbito criminológico en cuanto a la formulación de teorías explicativas, el mismo concepto de "delitos de cuello blanco" no ha llegado a poseer una definición unívoca y pacífica, hasta el punto de llegarse a cuestionar su idoneidad desde un punto de vista científico ${ }^{2}$. Sin embargo, partir de un concepto criminológico de delito de cuello blanco nos permitirá realizar reflexiones no ancladas sólo en la legislación penal de un solo Estado, sino en todos aquellos delitos que compartan las características propias de este tipo de criminalidad -a las que luego me referiré-. Por otro lado, desde el punto de vista de la justicia restaurativa, se plantearán, como veremos, problemas comunes de aplicación de la misma. Ello con independencia del necesario tratamiento monográfico de las concretas cuestiones que surjan de esta aproximación genérica.

En el terreno de la delincuencia de cuello blanco se discute además qué tipo de sanciones pueden ser las más apropiadas y la necesidad o no de resocialización de los condenados, lo cual conduce a plantearse las finalidades del Derecho penal en este ámbito ${ }^{3}$. La respuesta, tanto desde el control social informal

Derecho penal en la empresa. Parte general, $5^{\text {a }}$ ed., Tirant lo Blanch, Valencia, 2016.

2 En este sentido, vid. SERRANO MAÍlLO, A.: "El (sesgado) uso de los delitos de cuello blanco en los paradigmas antiempíricos", Revista de Derecho Penal y Criminología, $\mathrm{n}^{\circ} 14,2004$, p. 242. El mismo autor señala que se han realizado grandes esfuerzos por aclarar el concepto, aunque no se ha llegado a resultados satisfactorios. Un sector de la criminología ha propuesto otros conceptos como 'delito ocupacional', 'delitos corporativos', 'delitos políticos', 'delitos sin víctimas', criminalidad organizada, etc. Otros autores, en cambio, sostienen que es adecuado mantener esta categoría abstracta y estudiar sus conexiones con los delitos comunes (ob. cit. p. 243)

3 Sobre las sanciones que pueden ser más adecuadas y las finalidades que éstas pueden poseer, vid., entre otros, DE VICENTE MARTÍNEZ, R.: "Las sanciones penales en el ámbito de la delincuencia económica", Estudios de Criminología II. Ediciones de la Universidad de Castilla-La Mancha (Estudios 52), Cuenca, 1999; BAUCELLS LLADÓS, J.: "Sistema de penas para el delincuente económico", Cuadernos de Política Criminal, nº107, 2012, pp. 143-182; ARRIBAS LÓPEZ, E. “¿Reeducación y reinserción social del delincuente de cuello blanco?”, Diario La Ley, núm. 8464, 327/2015, de 22 de enero de 2015. 
como formal, también varía en función de los distintos países, atendiendo a su cultura y a su sensibilidad acerca de la protección de intereses colectivos ${ }^{4}$, en constante evolución a lo largo del tiempo. En ocasiones, incluso se plantea en este ámbito una posible desconexión entre la percepción pública, las costumbres judiciales y las acciones legislativas 5 . Todos estos factores, extremadamente complejos, deberán tenerse en cuenta a la hora de diseñar estrategias que respondan a este tipo de criminalidad.

Por otra parte, en lo relativo a la justicia restaurativa, pese a que en la actualidad contamos con una inabarcable bibliografía, no existe un concepto unívoco de la misma, aun cuando sí se encuentra un mayor consenso sobre los principios, garantías y finalidades que deben inspirar sus prácticas.

En un intento de sistematización de las diferentes propuestas a lo largo del tiempo, considero que se pueden distinguir dos momentos conceptuales: En primer lugar, aquellas primeras formulaciones teóricas situadas entre los años 70 y 80 del siglo pasado, como las de Nils CHRISTIE ${ }^{6}$ o Howard $\mathrm{ZERH}^{7}$, las cuales desarrollaremos con posterioridad. Las principales aportaciones de esa etapa son, a mi juicio, la denuncia de ciertos fallos en la justicia penal y la elaboración de un discurso legitimador de la justicia restaurativa, estableciendo sus diferencias con el

4 En relación con la corrupción, vid. los informes de Transparency International (https://www.transparency.org/), en especial el Índice de Percepción de la Corrupción que se publica cada año sobre numerosos países.

5 Vid., LUEDTKE, D.: "Progression in the Age of Recession: Restorative Justice and White-Collar Crime in Post-Recession America", Brooklyn Journal of Corporate Financial and Comercial Law, vol. 8, Issue 1, 2014, p. 315 .

6 Vid., CHRISTIE, N.: "Conflicts as Property", en The British Journal of Criminology, vol. 17:1 (Jan), 1977, p. 1 y ss. Un extracto de este texto se puede encontrar en CHRISTIE, N.: "Conflicts as Property", en JOHNSTONE, G. (Ed): A Restorative Justice Reader. Text, sources, context, Willan Publishing, 2003, p. 57 y ss.

7 Vid., ZEHR, H.: Changing lenses: a new focus for Crime and Justice, Scottsdale, PA, Herald Press, 1990; ZEHR, H.: "Retributive Justice, Restorative Justice", en JOHNSTONE, G. (Ed): A Restorative Justice Reader. Text, sources, context, Willan Publishing, 2003, p. 69 y ss. 
sistema de justicia penal. La segunda etapa, que temporalmente llega hasta nuestros días, es de consolidación de la justicia restaurativa, tanto a nivel práctico como a nivel teórico y normativo. En ella, podemos observar dos tendencias sobre la noción de justicia restaurativa. Por un lado, una concepción estricta, la cual incide en el proceso llevado a cabo y en el resultado reparador. Esta idea subyace en autores como Tony MARSHALL ${ }^{8}$, Andrew von HIRSH, Andrew ASHWORTH y Clifford SHEA$\mathrm{RING}^{9}$ y en los principales documentos de Naciones Unidas ${ }^{10}$ y de la Unión Europea ${ }^{11}$. Por otro lado, esta tendencia convive con una concepción amplia de justicia restaurativa en la que, como veremos, quizás se desdibujan los contornos de la misma. Exponentes de esta concepción amplia son, a mi juicio, con sus diferentes matizaciones, Paul McCOLD, Ted WHACHEL ${ }^{12}$, Lode WALGRAVE ${ }^{13}$, Martin WHRIGHT ${ }^{14}$, entre otros. En la

8 Vid., MARSHALL, T.F.: Restorative Justice. An Overview, Report by the Home Office Research Development and Statistics Directorate, 1999.

9 Von HIRSH, A./ ASHWORTH, A./ SHEARING, C.: "Specifying Aims and Limits for Restorative Justice: A 'Making Amends' Model?", en AA.VV.: Restorative Justice and Criminal Justice. Competing or Reconciliable Paradigms?, Hart Publishing, Oxford and Portland, 2003, p. 21 y ss.

10 Vid., Resolución 2002/12, del Consejo Económico y Social: "Principios básicos sobre la utilización de programas de justicia restaurativa en materia penal"

11 La Unión Europea todavía no ha aprobado ninguna Directiva sobre la justicia restaurativa de manera monográfica. Sin embargo, sí encontramos referencias a ella en la Directiva 2012/29/UE, del Parlamento Europeo y del Consejo, de 25 de octubre de 2012, por la que se establecen normas mínimas sobre los derechos, el apoyo y la protección de las víctimas de delitos, y por la que se sustituye la Decisión marco 2001/220/JAI del Consejo, con una definición de justicia reparadora en el art. 1 ap. d) de esta Directiva.

12 Vid., McCOLD, P./ WACHEL, T.: "Restorative Justice. Theory Validation", en WEITEKAMP/ KERNER (Eds): Restorative Justice. Theoretical Foundations, Willan Publishing, Devon, 2002, p. 110 y ss.

13 Vid., WALGRAVE, L.: "La justice restaurative (I):à la recherche d'une théorie et d'un programme" Criminologie, vol. 32, $\mathrm{n}^{\circ}$ 1, 1999; WALGRAVE, L.: "La justice restaurative et les victimes", Journal International de Victimologie (1)4, 2002; WALGRAVE, L.: "Integrating Criminal Justice and Restorative Justice", en JOHNSTONE, G./ VAN NESS, D.N.: Handbook of Restorative Justice, Willan Publishing, 2007, p. 559 y ss. 
normativa supranacional destaca la recomendación del Consejo de Europa de 2018 relativa a la justicia restaurativa en materia penal ${ }^{15}$.

Lo que nos proponemos en este trabajo es analizar, en cada una de estas tres conceptualizaciones de justicia restaurativa, la viabilidad y/o conveniencia de llevar a cabo iniciativas restaurativas en el ámbito de la delincuencia socioeconómica. Antes de ello, sin embargo, debemos aclarar el concepto de delincuencia de cuello blanco que utilizaremos en este trabajo.

\section{El concepto de delincuencia de cuello blanco del que par- timos}

Sobre el concepto de delito de cuello blanco (White-Collar Crime $)^{16}$ existen diversas posiciones que podemos agrupar en aquellas que se centran en las características del autor y las que atienden a las características del delito cometido ${ }^{17}$. Entre las primeras, destaca la obra de Edwin H. SUTHERLAND, quien por primera vez acuñó este concepto en 1939. Para este autor, se trata de "un delito cometido por una persona de respetabilidad y status social alto en el curso de su ocupación"18. De esta

14 WRIGHT, M.: "Restorative Justice: for whose benefit?", en EUROFORUMRJ (Ed): Victim-offender mediation in Europe. Making Restorative Justice Work, Leuven University Press, 2000, p. 19 y ss.

15 Vid., Recommandation CM/Rec (2018)8 du Comité des Ministres aux États membres relative à la justice restaurative en matière pénale. Esta Recomendación va mucho más allá que su predecesora, la cual se refería exclusivamente a la mediación penal (Recommandation $\mathrm{n}^{\circ} \mathrm{R}(99)$ du Comité des Ministres aux États membres sur la médiation en matière pénale).

16 A efectos de este trabajo utilizaremos de manera indistinta los términos "delito de cuello blanco" y "delito socioeconómico" o "delito económico".

17 Sobre esta cuestión, vid., por todos, MORÓN LERMA, E. "El perfil criminológico del delincuente económico", en GARCÍA ARÁN, M.: La delincuencia económica. Prevenir y sancionar, Tirant lo Blanch, Valencia, 2014 pp. 29-52.

18 Cfr., SUTHERLAND, E.H. El delito de cuello blanco, (trad. Rosa del Olmo), Ed. La Piqueta, 1993, p. 65. 
definición, y de la construcción teórica que subyace en ella, se han apuntado algunos aspectos que han sido objeto de crítica. En lo que aquí interesa destacar, se ha cuestionado desde un punto de vista empírico que el delincuente de cuello blanco deba ser siempre una persona con estatus económico alto y con una gran formación, ya que un gran porcentaje de ellos pueden no poseer las características que SUTHERLAND describe en sus estudios ${ }^{19}$.

Por otra parte, existen formulaciones de la delincuencia de cuello blanco que se centran más en las características del hecho cometido, oponiéndose a la delincuencia "común" o "callejera". En la línea seguida por Herbert EDELHERTZ20, el concepto manejado por EE.UU -concretamente, por el FBI- desde 1989 alude a " ... those illegal acts which are characterized by deceit, concealment, or violation of trust and which are not dependent upon the application or threat of physical force or violence. Individuals and organizations commit these acts to obtain money, property, or services; to avoid the payment or loss of money or services; or to secure personal or business advantage." ${ }^{21}$.

Dado que debemos partir de un concepto de delincuencia de cuello blanco, acogemos en este estudio esta última definición que se centra en el hecho delictivo cometido, el cual viene caracterizado por un modus operandi (engaño, ocultamiento, abuso de confianza, ausencia de amenaza de fuerza física o violencia) y por la finalidad perseguida por el sujeto activo del delito (para obtener dinero, bienes o servicios; para evitar el pago

19 Cfr. GABBAY, Z.D.: "Exploring the limits of the restorative justice paradigm: restorative justice and white-collar crime", Journal of Conflict Resolution, vol. 8.2, 2007, p. 429.

20 Según este autor, “...the term will be defined as an illegal act or seies of illegal acts committed by non physical means and by concealment or guile, to obtain money or property, to obtain busness or personal advantage" (EDELHERTH, H.: The nature, impact, and prosecution of white-collar crime, National Institute of Law Enforcement and criminal Justice, 1970, p. 3).

21 US, Department of Justice (USDOJ): White-Collar Crime: A Report to the Public, 1989, p. 3. 
o la pérdida de dinero o servicios o para asegurar una ventaja personal o comercial). Ello con independencia de que las especiales características del autor debamos tenerlas en cuenta -si concurren- para valorar la conveniencia y/o forma de llevar a cabo iniciativas restaurativas. Nos parece, a estos efectos, más acertada una definición que atienda a las características de la infracción cometida, dado que resultará más sencillo enlazarla con los tipos establecidos en los Códigos penales, los cuales deben describir conductas delictivas, tal y como corresponde en un Derecho penal centrado en la responsabilidad por el hecho cometido, a diferencia de lo que sucede en un derecho penal de autor.

\section{2. ¿Por qué resulta controvertida la justicia restaurativa en la delincuencia de cuello blanco?}

La delincuencia socioeconómica incluye una amplia amalgama de delitos, muy distintos entre sí: cohecho, tráfico de influencias, delitos urbanísticos, delitos contra los consumidores, delitos contra la salud pública, fraude de subvenciones, y un largo etc. ${ }^{22}$. Sin embargo, en lo que aquí nos interesa destacar, la mayor parte estos delitos poseen unas características distintas de la delincuencia clásica -0 , si se quiere, del núcleo duro del Derecho penal-, las cuales representan, cuando menos, un reto para llevar a cabo procesos de justicia restaurativa. Y la cuestión no resulta baladí, pues gran parte de los delitos tipificados en los Códigos penales actuales presentan este tipo de características ${ }^{23}$ :

22 En España podemos pensar en casos tan dispares como el desastre ecológico del Prestige, el caso de los ERE, caso Púnica, caso Bankia, caso Gürtel y, más antiguo, el caso del aceite de colza. Pero no sólo debemos tener presente los casos más mediáticos sino también aquellos otros que, quizás a menor escala y menos conocidos, forman parte de este tipo de delincuencia.

23 En cuanto a su prevalencia, los delitos de cuello blanco constituyen una importante área. A título ejemplificativo, algunos estudios apuntan a que este tipo de delincuencia constituye el $25 \%$ de los delitos federales condenados en EE.UU. Cfr. En GABBAY, Z.D.: "Exploring the limits of the restorative justice paradigm: restorative justice and white-collar crime", p. 430. Otros estudio de 2010, en este caso del National White Collar Crime Center y de 
Por una parte, en muchas ocasiones se trata de delitos que protegen bienes jurídicos supraindividuales o de carácter colectivo, como son el orden socioeconómico, el medio ambiente, la ordenación del territorio, los derechos de los trabajadores, la salud pública, el correcto funcionamiento de la Administración, etc. Y, generalmente, estos bienes jurídicos colectivos se encuentran tutelados en un estadio de peligro, ya sea de peligro abstracto o concreto. Respecto a la posibilidad de llevar a cabo procesos restaurativos, las características de estos delitos plantean problemas en cuanto a la identificación de una víctima y el contenido del daño provocado. A estos efectos se plantea: cuando se trata de delitos contra intereses Estatales, ¿pueden llevarse a cabo procesos restaurativos? ¿Es legítimo, de acuerdo con los principios de la justicia restaurativa, utilizar víctimas representativas u organizaciones representativas? Las estructuras de peligro, especialmente abstracto, no exigen para la consumación típica un daño material, ni siquiera la puesta en peligro concreta del bien jurídico. ¿Qué tipo de daño se genera en un delito de peligro? ¿Qué es necesario reparar y cómo?

Por otra parte, como ya se ha indicado en el apartado anterior, en algunas definiciones de delincuencia de cuello blanco se destacan diferencias significativas respecto al autor del delito en comparación con la delincuencia común. Aunque no todos los estudios criminológicos coinciden en el perfil del delincuente de cuello blanco, se describe en ocasiones al autor del delito como una persona con alta formación, que comete el delito en el ámbito de su profesión y se dibuja psicológicamente al delincuente de cuello blanco como una persona narcisista, carente de empatía, con capacidad de manipular y de utilizar el sistema legal en su propio beneficio ${ }^{24}$. Un sector de la doctrina considera que el ofensor raramente asume su responsabilidad por los

la Oficina de Asistencia Judicial en EE.UU, revelan que en 1 de cada 4 hogares estadounidenses hubo una víctima de un delito de cuello blanco en el año anterior (Cfr. LUEDTKE, D.: "Prograssion in the Age of Recession...", cit., p. 323).

24 Cfr. LUEDTKE, D.: "Progression in the Age of Recession...", cit., p. 330. 
hechos y, si lo hace, sólo es para obtener beneficios, como una sentencia penal más benévola. En el mejor de los casos, aun admitiendo objetivamente los hechos, el sospechoso o condenado por un delito de cuello blanco raramente admitirá ser responsable del mismo, en el sentido de que su conducta fuere dolosa o imprudente, sino que lo atribuiría a la mala suerte en los negocios o a imprevistos imponderables ${ }^{25}$. También se apunta una escasa capacidad de autocontrol (falta de control de impulsos y necesidad de vivir situaciones de riesgo), revelando algunos estudios a una baja puntuación en el rasgo de la personalidad conocido como "responsabilidad" (conscientiousness) ${ }^{26}$. Ello plantea problemas de aplicación de la justicia restaurativa, en especial atendiendo a las condiciones para comenzar un proceso restaurativo o a los principios que se deben observar en el proceso. Así, desde el punto de vista de la justicia restaurativa, se exige como condición para determinar la viabilidad de un asunto que el ofensor haya reconocido los elementos fácticos del caso, sin que ello suponga una declaración de culpabilidad en el sentido jurídico ${ }^{27}$. La capacidad del delincuente de cuello blanco para utilizar técnicas de neutralización que inhiben su responsabilidad ¿impediría considerar ab initio la viabilidad de un proceso restaurativo? Además, uno de los principios importantes del proceso restaurativo es un cierto equilibrio de poder entre las partes interesadas para mantener un diálogo y, en su caso, la adopción voluntaria de acuerdos restaurativos. En definitiva, un diálogo caracterizado por la "no dominación" de ninguna de las partes ${ }^{28}$.

25 Ob. cit., p. 234.

26 Vid., REDONDO ILlESCAS, S./ GARRIDO GENOVÉS, V.: Principios de Criminología, $4^{\mathrm{a}}$ ed., Tirant lo Blanch, Valencia, 2013, p. 793-794.

27 Vid. Art. 12.1 c) de la Directiva 2012/29/UE; Apartado II.8 de los Principios Básicos de Naciones Unidas sobre la utilización de programas de justicia restaurativa en materia penal (E/CN.15/2002/5/Add.1); Apartado V.30 de la Recomendación del Consejo de Europa $\mathrm{CM} / \operatorname{Rec}(2018 / 8)$ relative à la justice restaurative en matière pénale.

28 Cfr., Apartado II.9 de los Principios Básicos de Naciones Unidas sobre la utilización de programas de justicia restaurativa en materia penal (E/ CN.15/2002/5/Add.1); Apartado III.14 de la Recomendación del Consejo de Europa CM/Rec (2018/8) relative à la justice restaurative en matière pénale; Considerando 46 de la Directiva 2012/29/UE. 
¿Podría el delincuente económico abusar de su poder también en un proceso restaurativo? ${ }^{29} \mathrm{Si}$ está acostumbrado a negociar y carece de empatía ¿no plantea ello un desequilibrio respecto a las otras partes, impeditivo de cualquier proceso restaurativo?

A continuación, se abordarán todas estas cuestiones al hilo de la evolución del concepto de justicia restaurativa.

\section{Las primeras formulaciones teóricas y el fundamento de la justicia restaurativa en la delincuencia de cuello blanco}

La justicia restaurativa, y la mediación penal como instrumento más común, existe desde antaño en las tradiciones aborígenes en distintos continentes ${ }^{30}$. Con todo, se asiste desde hace algunas décadas a un nuevo impulso y crecimiento de la misma $^{31}$, de manera que, en palabras de Luis GORDILLO SANTANA, ésta "nace como sabia nueva dentro del "anquilosado" sistema jurídico de las sociedades occidentales" ${ }^{32}$. La explicación de tal resurgimiento y desarrollo se encuentra en múltiples

29 Se plantea esta cuestión GABBAY, Z.D.: "Exploring the limits of the restorative justice paradigm: restorative justice and white-collar crime", p. 453. Por su parte, LUEDTKE indica que la justicia restaurativa ha sido infrautilizada en Canadá en el ámbito de los delitos de cuello blanco porque se la concibe como una "válvula de escape", de manera que, si los acusados saben manipular el sistema, podrían escapar de ser sancionados penalmente ("Progression in the Age of Recession...", cit., p. 321).

30 Así, se indica que, aunque resurgió en Europa y América del Norte en los años 1970, ésta proviene de tradiciones muy antiguas de África, América Latina y Asia, así como las primeras naciones de Canadá y de Nueva Zelanda. Cfr., AERTSEN, I./ MACKAY, R./ PELIKAN, C/ WILLEMSENS, J./ WRIGHT, M.: Renouer les liens sociaux. Médiation et justice en Europe, Editions du Conseil de l'Europe, Cedex, Strasbourg, 2004, p. 18.

31 Existe un cierto consenso en la doctrina en situar la primera manifestación de justicia restaurativa en su versión actual en Canadá (Kitchener, Ontario), cuando en 1974 se realizó la primera mediación con dos jóvenes delincuentes. Vid., más ampliamente, AERTSEN, I./ MACKAY, R./ PELIKAN, C/ WILLEMSENS, J./ WRIGHT, M.: Renouer les liens sociaux..., cit., p. 16.

32 Cfr. GORDILLO SANTANA, L.F.: La justicia restaurativa y la mediación penal, Iustel, Madrid, 2007, p. 26. 
factores ${ }^{33}$. Uno de ellos es la crisis del modelo de justicia penal tradicional, con el desarrollo de movimientos a favor de la resolución alternativa de conflictos (Alternative Dispute Resolution) $\mathrm{y}$, desde una opción más radicalizada, las teorías abolicionis$\operatorname{tas}^{34}$. También cobra especial relevancia entre los factores impulsores de la justicia restaurativa la recuperación de la atención a los intereses y necesidades de la víctima ${ }^{35}$. Además, se cuestionan el modelo retributivo y resocializador, especialmente por la utilización de la pena privativa de libertad como el principal instrumento para alcanzar sus fines. En este último aspecto, la justicia restaurativa comparte protagonismo con el desarrollo de las penas alternativas a la prisión ${ }^{36}$. Las primeras formulaciones teóricas de la justicia restaurativa intentan establecer el fundamento de su intervención, señalando diferencias entre la aproximación restaurativa y el sistema de justicia penal. Veamos a continuación sus propuestas.

\subsection{Las primeras exposiciones teóricas de la justicia restaurativa}

Destaca entre las primeras elaboraciones teóricas la obra de Nils CHRISTIE, en su conocido trabajo "Conflicts as property”, donde se denuncia la sustracción por parte de Estado de los conflictos que pertenecen a las partes directamente implicadas ${ }^{37}$.

33 Vid., de forma más amplia, por todos, GORDILLO SANTANA, L.F.: La justicia restaurativa ... cit., p. 77 y ss.

34 Cfr. VARONA MARTÍNEZ, G.: La mediación reparadora como estrategia de control social. Una perspectiva criminológica, Comares, Granada, 1998, pp. 140 y ss.

35 Vid., ampliamente, ALASTUEY DOBÓN, C.: La reparación a la víctima en el marco de las sanciones penales, Tirant lo Blanch, Valencia, 2000, p. 35 y ss.

36 En este sentido, TAMARIT SUMALLA sostiene que es conveniente situar las críticas al pensamiento de la resocialización en sus justos términos. Considera que si alguna cosa se debe desterrar no es precisamente este ideal, sino los medios con los que se pretendía conseguirlo, esto es, con la pena privativa de libertad. Cfr. La reparació a la víctima en el Dret penal. Estudi i crítica de les noves tendències político-criminals, Justícia i Societat, núm. 11, 1993.

37 Vid., CHRISTIE, N.: "Conflicts as Property", en JOHNSTONE, G. (Ed): A Restorative Justice Reader ..., cit. p. 61. 
Este autor sostiene que los conflictos deben llegar a ser útiles para las personas implicadas originariamente en el conflicto. El Estado, al atribuirse la propiedad sobre el mismo, provoca una serie de pérdidas, tanto para la víctima como para el ofensor y la comunidad en su conjunto.

En cuanto a la sociedad, se imposibilita que los ciudadanos participen en las tareas que directamente les afectan y se les priva de la oportunidad pedagógica que supondría la aclaración de la norma. En este punto, CHRISTIE critica la tarea de los abogados, puesto que seleccionan y deciden ante su representado aquellas cuestiones que son importantes y las que no lo son legalmente ${ }^{38}$.

Por otra parte, la víctima es quizás la que más pierde ya que sufre una doble pérdida. En primer lugar, en relación con el delincuente y, en segundo lugar, siéndole negado el derecho de participación completa en un asunto importante en su vida. Y no sólo a la víctima le es usurpada la remuneración material que podría recibir como compensación del daño - puesto que las multas las acaba percibiendo el Estado-, sino que pierde algo quizás más importante, como es la propiedad del conflicto y su participación en la solución de una de las cuestiones que podría ser importante en su vida ${ }^{39}$.

Finalmente, respecto al ofensor, aun reconociendo CHRISTIE que se trata de una cuestión compleja, considera que éste pierde la posibilidad de participar en la discusión, la oportunidad de explicarse a la víctima y, sobre todo, la posibilidad de ser perdonado. Cierto es que, según el autor, comparado con las humillaciones que puede sufrir el ofensor delante de un Tribunal no es un mal negocio y que el acusado podría preferir una distancia respecto de la víctima y de la comunidad y desear un proceso legal con su vocabulario característico y sus expertos legales. No obstante, sostiene que estos potenciales beneficios deberían estar presentes independientemente de los deseos del autor del

38 Ob.cit.p.61.

39 Ob. cit. p. 59. 
delito y plantea la siguiente pregunta: ¿estamos dispuestos a darles esta salida fácil? $?^{40}$.

A mi juicio, esta última reflexión puede contribuir a soslayar algunas de las mayores críticas que se han realizado a la justicia restaurativa, esto es, que por su procedimiento o por sus resultados, se trata de una respuesta menos contundente que el sistema de justicia penal, observación que ha constituido uno de los principales motivos para negar, por parte de algunos, su viabilidad en el caso de delitos graves ${ }^{41}$. Sin embargo, la cuestión planteada por CHRISTIE no está exenta de críticas. Aun cuando el autor especifica que su concepción no es ajena a un interés en el tratamiento o mejora de los delincuentes, debemos poner de manifiesto que tal afirmación podría conducir a la aplicación de la justicia restaurativa más allá de los casos en los que exista una voluntariedad de las partes, soslayando uno de los principios fundamentales de los procesos restaurativos. Una concepción punitivista o estigmatizadora del delincuente entendemos que también sería contraria a los principios que deben inspirar los procesos de justicia restaurativa.

Por otra parte, ha contribuido de forma muy significativa a la conceptualización de la justicia restaurativa la obra de Howard ZEHR, el cual califica la justicia restaurativa de nuevo paradigma, en contraposición al sistema de justicia penal actual $^{42}$. Este autor, crítico con la justicia penal, afirma en la línea de CHRISTIE que este sistema no trabaja ni para los delincuentes ni para las víctimas. Estas últimas tienen necesidades de respuestas importantes que no pueden encontrar en el sistema de justicia penal, tales como hablar de sus emociones frente al

40 Ob. cit. p. 62.

41 Afirma que el carácter de favor que, a menudo, se le ha atribuido a la mediación ha sido un obstáculo para su aplicación en los casos de infracciones graves, AERTSEN, I.: "La médiation victime délinquant en cas d'infraction grave", en AA.VV: Politique pénale en Europe, Council of Europe Publishing, 2005, p. 81.

42 Vid., ZEHR, H.: "Retributive Justice, Restorative Justice", en JOHNSTONE, G. (Ed).: A Restorative Justice Reader ... cit., p. 69 y ss. 
delito, recibir una restitución, experimentar la justicia y una experiencia de perdón. Apunta el autor que el sistema penal, por el contrario, lo único que hace es implicarlas como testigos, si este testimonio es necesario para la declaración de culpabilidad del autor, pero en ningún caso participarán directamente en su propio caso.

El sistema de justicia penal tampoco proporcionaría, según ZEHR, aquello que necesitan los delincuentes puesto que, si bien los Jueces y Tribunales hablan a menudo de la responsabilidad de los mismos, ésta se entiende generalmente como la imposición de un castigo. ZEHR sostiene que la verdadera responsabilidad significa algo absolutamente diferente, que tiene que ver con el entendimiento de las consecuencias humanas de las propias acciones ${ }^{43}$. El proceso penal no sólo no anima a una verdadera asunción de responsabilidad del delincuente -al no ofrecer al mismo la oportunidad de entender las implicaciones de sus actos- sino que además desalienta activamente la asunción de responsabilidad, al desviar la atención a cuestiones puramente legales y fomentar en el proceso que el autor se centre en evitar la imposición de una sanción ${ }^{44}$. De este modo, el punto central en el procedimiento penal es la declaración de la culpabilidad, focalizando en consecuencia su interés en el pasado y no en el futuro. Considera que el fracaso de otros intentos en el pasado se debe a que se han planteado programas alternativos, sin ofrecer valores alternativos. Así, afirma que se necesita una visión alternativa, no simplemente sentencias alternativas ${ }^{45}$, en su conocida metáfora "changing lenses", que constituye a su vez el título de una de sus publicaciones más importantes ${ }^{46}$.

El autor aboga por un nuevo paradigma restaurativo que modificaría la comprensión del delito y de la justicia. Se

\footnotetext{
43 Ob. cit. p. 69.

44 Ob.cit.p. 70.

45 Ob. cit. p. 80

46 Vid., ZEHR, H.: Changing lenses: a new focus for Crime and Justice, Scottsdale, PA, Herald Press, 1990.
} 
definiría el delito como una violación de una persona respecto a otra y no ya como una ofensa contra el Estado ${ }^{47}$. De este modo, plantea la posibilidad de trabajar en un sistema de justicia restaurativa separada, paralela al anterior y sin sustituir a esta última $^{48}$. ZEHR contrapone el paradigma restaurativo respecto al retributivo ${ }^{49}$, al igual que también se ha contrapuesto en ocasiones respecto al sistema rehabilitador ${ }^{50}$.

\section{2. ¿Existe un fundamento de aplicación de la justi- cia restaurativa en la delincuencia de cuello blanco?}

Teniendo en cuenta las primeras formulaciones de la justicia restaurativa acabadas de exponer, podemos inferir que la justicia restaurativa, conceptualizada de este modo, no sería aplicable a la delincuencia de cuello blanco, al menos en la mayor parte de delitos que la integrarían. Así, en primer lugar, no se produciría en este caso una "sustracción del conflicto" a las partes directamente implicadas (esencialmente entre víctima y ofensor), puesto que en estos casos el delito no es contra una persona concreta, sino contra el funcionamiento del Estado, en su orden económico, en su administración, en sus finanzas, en la ordenación de su territorio, etc. También podría tratarse de delitos que afectan a toda la sociedad en general (medio ambiente) o a sectores concretos - pero muy amplios- de la misma (trabajadores, consumidores, accionistas, entre otros).

En segundo lugar, tampoco podría seguirse en la delincuencia de cuello blanco la definición de delito propuesta por estos autores, como "ofensa de un individuo contra los derechos de otro" o "violación de una persona respecto de la otra", que

47 Cfr., ZEHR, H.: "Retributive Justice, Restorative Justice". cit. p. 79.

48 Ob. cit.p. 80 .

49 Sobre esta cuestión, vid., ampliamente, ZEHR, H.: "Retributive Justice, Restorative Justice", cit., p. 81-82.

50 Vid., por todos, un cuadro explicativo donde se contrapone la perspectiva rehabilitadora, la reparadora y restaurativa en KELLENS, G.: Punir. Pénologie et droit des sanctions pénales, Éditions Juridiques de l'Université de Liège, Liège, 2000, p. 51-52. 
claramente apelan a bienes jurídicos personales, donde existe una víctima concreta. En definitiva, en gran parte de los delitos de cuello blanco el conflicto sería propiamente con el Estado, o con la sociedad, porque se trata de bienes jurídicos supraindividuales. Como apunta la doctrina penal, estos bienes jurídicos poseen una titularidad compartida por el conjunto de la sociedad, siendo bienes indisponibles (el consentimiento carece de eficacia jurídico-penal) e indivisibles (imposibilidad ni fáctica ni jurídica de dividir los bienes jurídicos, de manera que pueda atribuirse una parte de manera individual $)^{51}$.

Sin embargo, respecto a estos autores clásicos, creo que cabe reflexionar sobre una cuestión: en todas estas obras subyace, con mayor o menor acierto o exactitud, una crítica al sistema de justicia penal, apelando a la existencia de necesidades no cubiertas por éste, que los autores explican respecto a ofensas de carácter personal. La pregunta que cabe plantearse es si, en el ámbito de la delincuencia de cuello blanco, existen necesidades no cubiertas por el sistema de justicia penal y si la justicia restaurativa puede contribuir a alcanzar -también en este ámbito- una respuesta más global y satisfactoria en la delincuencia socioeconómica.

A parte de la gran cifra negra que se intuye que existe en los delitos de cuello blanco ${ }^{52}$, en aquellos casos que son

51 Vid., más ampliamente, MARTÍNEZ-BUJÁN PÉREZ, C.: Derecho penal económico..., cit., p. 188-189.

52 En este sentido, ZÚÑIGA RODRÍGUEZ, L.: "Culpables, millonarios e impunes: el difícil tratamiento del derecho penal del delito de cuello blanco", IUS, núm. 35, 2015, p. 53. Esta autora sostiene que en muchos casos no se llegan a perseguir penalmente estos delitos $\mathrm{y}$, aunque se persigan, no concluyen en condenas y, si se condena, no se imponen penas de prisión, de manera que la persecución penal es, en estos delitos, bastante selectiva. Por otra parte, vincula la falta de identificación de una víctima como uno de los mayores problemas para la persecución de los delitos de corrupción, puesto que afecta a la puesta en conocimiento de estos delitos a las autoridades para la incoación de diligencias penales, PLANCHADELL GALLARDO, A.: "Las víctimas en los delitos de corrupción (panorama desde las perspectivas alemana y española), Estudios Penales y Criminológicos, vol. XXXVI, 2016, p. 70. 
objeto de persecución penal se ha puesto de manifiesto que la Administración de Justicia es lenta y costosa y requiere una gran especialización de Fiscales, Jueces y Peritos para llegar a verificar los hechos probados constitutivos de infracción penal ${ }^{53}$. Ello provoca un gran coste económico y unas sentencias muy alejadas en el tiempo de la comisión de los hechos delictivos ${ }^{54}$. Sobre esta cuestión, entiendo que la justicia restaurativa tiene poco que ofrecer pues, por la complejidad de los delitos cometidos, será necesaria en todo caso una investigación exhaustiva de los hechos, cosa que requerirá, al menos, de una labor de la Policía Judicial, de los Fiscales y de los Jueces de Instrucción. Así, se rechaza el argumento -en ocasiones esgrimido como beneficio por los defensores de la intervención restaurativa-, de que los procesos restaurativos suponen una descarga de trabajo y de coste económico a la Administración de Justicia. Aunque en algunos casos pudiera ser así como efecto colateral, sobretodo en delitos menos graves o de bagatela, no es el caso de la delincuencia económica. En este sentido, considero que la justicia restaurativa debe funcionar como complemento de sistema penal, y no como alternativa, en la línea de la mayor parte de la doctrina que se ocupa actualmente de la justicia restaurativa ${ }^{55}$.

Especialmente en los delitos socioeconómicos, considero que la intervención de la justicia penal puede ser relevante en ciertos casos, si no se quiere correr el riesgo de contribuir a un aumento de la sensación de impunidad y de trato de favor del delincuente de cuello blanco. Por lo tanto, entiendo que en

53 Sobre estas cuestiones, vid., ampliamente, REBOLLO VARGAS, R./ CASAS HERVILLA, J.: "El proceso penal y la investigación de la delincuencia económica”, en GARCÍAARÁN, M. (Dir): La delincuencia económica. Prevenir y sancionar, cit., p. 335 y ss.

54 En este sentido, GABBAY, Z.D.: "Exploring the limits of the restorative justice paradigm: restorative justice and white-collar crime", p. 432.

55 En el ámbito específico de los delitos de cuello blanco, sostiene que la justicia restaurativa no ofrece una alternativa al sistema existente como puede ser en otros delitos, sino que debe utilizarse como complemento del sistema de justicia penal, GABBAY, Z.D.: "Exploring the limits of the restorative justice paradigm: restorative justice and white-collar crime", p. 440-441. 
ocasiones los efectos simbólicos de una sentencia condenatoria no deben desdeñarse ${ }^{56}$. El reconocimiento de los hechos a través de una sentencia puede ser importante desde el punto de vista social, como reconocimiento de la verdad de lo sucedido, a partir del cual se puedan idear mecanismos de reparación, donde la justicia restaurativa pueda tener un papel relevante. Así, dependiendo de la gravedad del delito socioeconómico realizado, la intervención restaurativa podría tener el mismo espacio que en la actualidad posee ésta respecto a los delitos graves y violentos, donde suele operar como complemento, sin que por ello se elimine por completo la intervención del sistema de justicia penal ${ }^{57}$.

Sin embargo, no se desconoce que, en algunos casos, la averiguación de los hechos se produce a través de "insiders" es decir, de coimputados o personas que han trabajado en la misma empresa o institución donde se ha producido el delito. El ordenamiento jurídico-penal posee algunos instrumentos en estos casos, como la utilización de sentencias de conformidad más benignas, la aplicación de la atenuante de confesión o de reparación de daño. Con todo, gran parte de la doctrina ha señalado algunos inconvenientes de aplicación de estas instituciones. Así, en España, en el caso de la atenuante de reparación, se ha señalado

56 En el mismo sentido, GARCÍA RÁN, M.: "Algunas bases para la justicia restaurativa en la delincuencia socioeconómica", Libro Homenaje a DiegoManuel Luzón Peña (en prensa), al afirmar que "en bienes jurídicos colectivos o supraindividuales, es aconsejable no renunciar al valor de la reparación "social" que tiene la celebración de un juicio que concluye con condena (p. 9). Una opción más radicalizada de la aquí sostenida, LUEDCTKE, quien afirma que en los casos de delitos de cuello blanco siempre deberían ser enjuiciados como si no fueran elegibles para la justicia restaurativa y luego, en su caso, modificar las consecuencias penales (en "Pregression in the Age of Recession...", cit., p. 334). Sin embargo, este argumento resulta menos factible en España, donde no existe una separación temporal entre la declaración de culpabilidad del autor (donde se establecen también los hechos probados) y la determinación de la pena (donde normalmente se acumula la acción civil).

57 En sentido similar, GABBAY, Z.D.: "Exploring the limits of the restorative justice paradigm: restorative justice and white-collar crime", p. 444. 
que en la mayor parte de ocasiones se aprecia, simplemente, por la consignación de una cantidad del dinero en la cuenta de un Juzgado, sin mayor atención al daño producido, a las necesidades de la víctima o la voluntad de reparación del investigado ${ }^{58}$. Por otro lado, en el caso de la conformidad, se ha denunciado que en muchas ocasiones se convierte en una negociación de última hora entre Ministerio Fiscal y Abogado defensor a la puerta del juzgado, en el que se negocia una pena a cambio de un reconocimiento parcial de los hechos ${ }^{59}$.

Mejorar estas instituciones e introducir en ellas una perspectiva restaurativa merece ser objeto de atención. Máxime cuando en España, del total de sentencias condenatorias en 2018, un $62 \%$ lo fueron en estricta conformidad, lo que supone el $47 \%$ del volumen global de sentencias ${ }^{60}$, llegando en EE.UU a más del $95 \%$ de los procesos penales, tanto a nivel federal como estatal ${ }^{61}$. A mi juicio, la justicia restaurativa podría ofrecer un complemento que sirva de mejora en la aplicación de las sentencias de conformidad y a las circunstancias atenuantes antes mencionadas, a través de procesos más cercanos al daño producido, a las necesidades de reparación y con una intervención más directa por parte de los autores de los delitos de cuello blanco y diversos actores sociales que pudieran compensar el desequilibrio existente entre autores del delito y perjudicados ${ }^{62}$. Con todo, serían necesarias reformas procesales en orden a establecer un

58 Sobre el contenido y alcance de la atenuante de reparación, vid., TAMARIT SUMALLA, J.M. "La difícil asunción de la reparación penal por la jurisprudencia española”, Revista General de Derecho Penal, Iustel, núm. 7, 2007.

59 Aun aportando ventajas, como la agilización de la justicia o la evitación de las consecuencias de un juicio, advierte de grandes inconvenientes de la conformidad, como el riesgo de frivolidad propio de una negociación competitiva, el impacto desigual en los imputados o la postergación de los intereses de la víctima, TAMARIT SUMALLA, J.M.: "La justicia restaurativa: concepto, principios, investigación y marco teórico", en TAMARIT SUMALLA, J.M. La justicia restaurativa: desarrollo y aplicaciones, Comares, Granada, 2012, p. 22. El mismo autor aboga por gestionar la conformidad en términos más cercanos a una racionalidad restaurativa (ob.cit).

60 Cfr., Memoria de la Fiscalía General del Estado, Madrid, 2019. Disponible en: https://d3cra5ec8gdi8w.cloudfront.net/uploads/documentos/2019/09/10/_memoria2019_76609dd4.pdf 
trámite de suspensión ad hoc del procedimiento penal por seguimiento de un proceso restaurativo, que permitiera con posterioridad, si la autoridad judicial lo estima pertinente, tener en cuenta los resultados de éste ${ }^{63}$. De acuerdo con las reflexiones precedentes, entiendo que resulta pertinente incidir sobre algunas aportaciones de los primeros teóricos de la justicia restaurativa, que podrían ser aplicables a la delincuencia socioeconómica:

Por una parte, considero que resultan aplicables a la delincuencia de cuello blanco las reflexiones de CHRISTIE acerca de los beneficios para la sociedad de la justicia restaurativa, en cuanto a la oportunidad pedagógica que supondría la aclaración de la norma. En este sentido, se debe tener en cuenta que, parte de la delincuencia socioeconómica comparte la tendencia político-criminal del Derecho penal del riesgo, donde existe una actividad lícita -regulada por la normativa extrapenal- y otra ilícita, sancionada administrativa o penalmente. Así, en palabras de Carlos MARTÍNEZ-BUJÁN PÉREZ ${ }^{64}$, se trata de bienes

61 En este sentido, cfr., LASCURÁIN SÁNCHEZ, J.A./ GASCÓN INCHAUSTI, F.: “¿Por qué se conforman los inocentes?, Indret, 3/2018.

62 En esta línea, propone de lege ferenda la creación de un proceso especifico ad hoc, diferente de la conformidad, VARONA MARTÍNEZ, G.: "Elementos victimológicos en la definición de la necesidad de pena. Aportaciones críticas desde la justicia restaurativa”, en JUANATEY DORADO, C./ SÁNCHEZ-MORALEDA VILCHES, N.: Derechos del condenado y necesidad de pena, Aranzadi, Navarra, 2018, p., 83.

63 Como es sabido la influencia restaurativa en la justicia penal puede venir por el reconocimiento de ciertos efectos jurídicos, adoptando una sentencia de conformidad, aplicando la atenuante de reparación o teniéndola en cuenta como un indicio más en la suspensión de la pena, el acceso al tercer grado penitenciario o a la libertad condicional. Vid, ampliamente, por todos, TAMARIT SUMALLA, J.: "La articulación de la justicia restaurativa con el sistema de justicia penal", en TAMARIT SUMALLA, J. (Coord).: Justicia restaurativa ... cit., p. 61 a 88 . Considero que debe descartarse una apreciación automática de estos efectos jurídicos en caso de concluir satisfactoriamente un proceso restaurativo y que sus efectos jurídicos deben ser siempre valorados y reconocidos por una autoridad judicial. Una de las ventajas de este reconocimiento judicial es la posibilidad de seguir de una manera más efectiva el cumplimiento del acuerdo restaurativo.

64 Cfr., MARTÍNEZ-BUJÁN PÉREZ, C.: Derecho penal económico..., cit., p. 190. 
jurídicos de "naturaleza conflictual", en la medida en que son actividades donde existen márgenes de licitud y de utilidad social y, por lo tanto, deben ser sometidas a control. Sólo cuando exceden de los límites fijados podrían ser sancionadas, pero no pueden ser prohibidas en todas sus manifestaciones. Tal es el caso, por ejemplo, del sector del medio ambiente o del urbanismo. La función pedagógica sobre los umbrales de licitud e ilicitud me parecen importantes en este ámbito. Y no sólo respecto al autor del delito, sino también para los perjudicados y para el sector social más cercano al delito. Ello se vincula con la función preventivo-general positiva de la pena, a la que la justicia restaurativa podría coadyuvar. La naturaleza conflictual de estos bienes jurídicos también se manifiesta en que, en ocasiones, los afectados o los perjudicados por el delito pueden, al mismo tiempo, haber contribuido al mismo. Piénsese, por ejemplo, en un delito urbanístico, donde se debe proceder a un derribo de viviendas para reparar los efectos del delito. La dicotomía propia del sistema de justicia penal, que clasifica a los sujetos como imputados, víctimas o perjudicados, en ocasiones no puede contemplar la complejidad de una doble posición, en la que la víctima no es "ideal" o "del todo inocente", sino que ha contribuido a la realización del delito. La justicia restaurativa, por la flexibilidad y contenido de sus procesos, puede estar en disposición de acoger un enfoque más matizado y no dicotómico de las posiciones autor-víctima, a la vez que puede proporcionar un espacio donde se resalte la importancia de la salvaguarda de los intereses colectivos vulnerados por la comisión del delito, realizando una labor preventiva ${ }^{65}$.

Por otra parte, recobra también importancia el concepto de responsabilidad que apuntaba Howard ZEHR, en el sentido de que la verdadera responsabilidad radica en entender las

65 No obstante, se requiere mayores esfuerzos en la justicia restaurativa para enfatizar esta cuestión, sobre todo si se pretende aplicar a la delincuencia socioeconómica. Apunta DIGNAN que no es una tendencia generalizada (DIGNAN, J., Understandig victims and restorative justice, Open University Press, McGraw-Hill, 2005, p. 175). 
consecuencias que han tenido los actos realizados. Ello resulta particularmente relevante en el ámbito de la delincuencia de cuello blanco, donde la anomia es uno de los factores explicati$\operatorname{vos}^{66}$, ya sea por características personales del autor del delito, ya sea por el alejamiento o separación física entre la conducta del ofensor y el daño o interés colectivo afectado ${ }^{67}$, cuando no por la intervención de diversas personas en el delito, generándose una suerte de "irresponsabilidad organizada" 68 . Alejándonos de actitudes moralizantes como la "vergüenza" ${ }^{69}$, y más cercanas a la comprensión del impacto provocado por el delito, la justicia restaurativa podría coadyuvar a una mayor prevención especial positiva en este terreno. Si entendemos la reinserción como la capacidad de vivir una vida en libertad sin la comisión de delitos, existen condenados por delito de cuello blanco que sí precisarían de reinserción, pues la comisión de uno o varios delitos de este tipo revelarían la falta de respeto a ciertas normas básicas de convivencia. Considero que puede resultar útil explorar las vías que ofrece la justicia restaurativa para mejorar la reinserción del delincuente de cuello blanco, máxime cuando, desde el punto de vista de la justicia penal, queda mucho camino

66 Sobre las teorías de la anomia, en sus diferentes formulaciones, vid. GARCÍA-PABLOS DE MOLINA, A.: Tratado de Criminología, $3^{\mathrm{a}}$ ed., Tirant lo Blanch, Valencia, 2003, p. 787 y ss.

67 Vid., LUEDKE, D.: "Progression in the Age of Recession...", cit., p. 324.

68 En este sentido, SCHÜNEMANN describe una "actitud criminal colectiva", consistente en el reconocimiento de que en el seno de una empresa se puede producir, debido a procesos de aprendizaje, conductas uniformes del conjunto que lesionan determinados bienes jurídicos ya que las personas, cuando están integradas dentro de una colectividad, llevan a cabo acciones que individualmente no serían capaces de realizar (vid., SCHÜNEMANN, B.: "La punibilidad de las personas jurídicas desde la perspectiva europea", en Hacia un Derecho penal económico europeo, Jornadas en homenaje al Prof. Klaus Tiedemann, BOE, 1995, p. 571).

69 En el ámbito de la justicia restaurativa, se ha trabajado el concepto de la vergüenza reintegradora (reintegration shaming), originada en las conferencias como un proceso psicológico por el cual el delincuente comparte la desaprobación que expresa la comunidad por sus acciones delictivas (vid. BRAITWAITE: Crime, Shame and Reitegration, University Press, Cambridge, 1989). 
para recorrer en orden al diseño de programas de reinserción para los mismos.

Respecto a la reparación del delito, considero que el sistema de justicia penal también presenta carencias en este ámbito. En este sentido, la determinación de la responsabilidad civil derivada del delito es sumamente difícil en algunos casos. No sólo por los daños cuantiosos que se pueden producir, sino también por la escasa investigación de la capacidad económica real del condenado para satisfacerla. El contenido de la reparación, como apuntábamos, puede resultar complejo en delitos contra bienes jurídicos colectivos de naturaleza estatal. Además, el concepto de víctima y la conciencia de victimización presentan especiales características en este ámbito delincuencial, sobre las que no se ocupan las primeras formulaciones teóricas de la justicia restaurativa, centradas en la victimización individual. Todo ello será abordado con posterioridad. Sin embargo, cabe destacar en este momento una de las reflexiones efectuadas por Nils CHRISTIE en 1977. Critica este autor que, llegándose a establecer una responsabilidad penal, las multas las acaba percibiendo el Estado ${ }^{70}$. Repensar de manera restaurativa la delincuencia de cuello blanco podría plantear el establecimiento de procedimientos por los cuales se destine la multa o el comiso a actividades sociales de reparación, de manera que el daño social provocado por el delito pueda ser en parte compensado. En este ámbito, Adán NIETO da cuenta de algunas iniciativas llevadas a cabo en el ámbito de la responsabilidad de las personas jurídicas, a la vez que realiza algunas propuestas, como el establecimiento de "multas en beneficio de la comunidad", que irían destinadas a proyectos en las comunidades afectadas y en las que éstas intervendrían en el proceso para decidir en qué proyectos o acciones se invierten las multas impuestas a las empresas ${ }^{71}$.

70 Cfr., CHRISTIE, N.: "Conflicts as property", cit., p. 61, aunque para este autor lo más importante no es que el Estado se quede con las multas, sino que propiamente se robe el conflicto en sí mismo a las partes interesadas.

71 Vid., NIETO, A.: "Empresas, víctimas y sanciones restaurativas: ¿Cómo configurar un sistema de sanciones para personas jurídicas pensando en sus 
En definitiva, podemos concluir que, de acuerdo con las primeras conceptualizaciones de justicia restaurativa, ésta sería inviable en la delincuencia socioeconómica. No puede constituir una alternativa a la justicia penal ni puede fundamentarse en la desposesión por parte del Estado de un conflicto entre sujetos individuales. Sin embargo, también en la delincuencia de cuello blanco se presentan algunas necesidades que no pueden ser del todo cubiertas por el sistema de justicia penal, lo cual conduce a plantear la legitimidad de la intervención de la justicia restaurativa como complemento del sistema de justicia penal en este ámbito. La cuestión a analizar a continuación es ¿de qué manera? ¿Tiene la justicia restaurativa herramientas para mejorar la respuesta al delito socioeconómico? Para ello, resulta necesario abordar el concepto de justicia restaurativa en su etapa de consolidación.

\section{La consolidación de la justicia restaurativa}

Quizás debido a muchos de los factores explicativos del resurgimiento de la justicia restaurativa que hemos expuesto más arriba ${ }^{72}$, la mayor parte de sus prácticas a partir de los años 70 del siglo pasado se refieren a delitos menos graves y en una fase anterior al juicio, o en la justicia juvenil ${ }^{73}$, tradicionalmente banco de pruebas de iniciativas innovadoras ${ }^{74}$. Sin embargo, gracias al éxito de tales prácticas y a los resultados empíricos obtenidos $^{75}$, la mediación y otras prácticas restaurativas se van

víctimas?", en HOYOS SANCHO, M. La víctima del delito y las últimas reformas penales, Aranzadi, Navarra, 2017, p. 323.

72 Vid., supra, inicio del apartado 3.

73 AERTSEN, I.: "La médiation victime-délinquant en cas d'infraction grave", cit., p. 81.

74 TAMARIT SUMALLA, J.M.: "La justicia reparadora y su articulación con el sistema penal" en TAMARIT SUMALLA, J.M./ VILLACAMPA ESTIARTE, C.: Victimología, justicia penal y justicia reparadora, Grupo Editorial Ibáñez, Colombia, 2006, p. 346.

75 Vid, por todos, TAMARIT SUMALLA, J.: "Justicia restaurativa: concepto, principios, investigación y marco teórico", cit., p. 30 y ss. 
extendiendo progresivamente. $\mathrm{Y}$ es sobre todo a partir de los años 90 cuando se produce una expansión de la justicia restaurativa, tanto de sus prácticas como de su reconocimiento estatal e internacional. Desde el punto de vista práctico, la mediación y otros procesos restaurativos se aplican en delitos graves ${ }^{76}$ y en cualquier estadio del proceso penal -incluyendo la ejecución de la pena $-{ }^{77}$, por lo que poco tiene que ver con las posiciones abolicionistas de algunos de los primeros teóricos.

En esta segunda etapa se sostiene, en cambio, que la justicia restaurativa debe dejar de definirse en negativo, es decir, en contraposición a los sistemas punitivos y resocializadores. En este sentido, como afirmaba Tony PETERS ${ }^{78}$, ésta no debe situarse al lado o contra el sistema actual de justicia penal, sino que debe ser pensada como complemento del mismo, sin que por ello pierda su identidad primigenia. Existiendo diferentes modos de concebir la justicia restaurativa, agrupamos las distintas manifestaciones en aquellas que adoptan un concepto estricto y las que, por el contrario, amplían los horizontes de aplicación de la misma. Veamos cada una de ellas con mayor detenimiento.

\subsection{Concepto estricto de Justicia Restaurativa}

Como ya habíamos avanzado, un concepto estricto de justicia restaurativa hace hincapié en el proceso seguido para la resolución de las cuestiones que plantea el delito, caracterizado

76 Para una descripción y evaluación de sus resultados, vid., entre otros, UMBREIT, M.S./ VOS, B./ COATES, R.B./ ARMOUR, M.P.: "Victims of severe violence in mediated dialogue with offender: the impact of the first multisite study in the US", International Review of Victimology, vol. 13, 2006.

77 Sobre un análisis de la justicia restaurativa en prinsión, incluyendo prácticas en diferentes países, vid. GUARDIOLA LAGO, M.J.: "Desarrollo y aplicaciones de la justicia restaurativa en prisión", en TAMARIT SUMALLA, J. (Coord): La justicia restaurativa, desarrollo y aplicaciones, Comares, Granada, 2012, pp. 183-236.

78 Vid., PETERS, T. "Victimisation, médiation et pratiques vers la réparation", CARIO, R./ SALAS, D.: Oeuvre de justice et victimes, Vol. 1, L'Harmattan, Sciences Criminelles, 2001, p. 238. 
por la intervención de sujetos distintos a los que implica el sistema penal y más cercanos al hecho cometido, con la observancia de unos principios y con la ayuda de un facilitador ${ }^{79}$. El proceso restaurativo perseguirá unas finalidades, que podemos concretar en la idea de reparación o restauración en sentido global, atendiendo a la reparación a la víctima, la recuperación del autor del delito y la reparación a la comunidad.

En este sentido, destaca la definición de Tony MARSHALL, el cual describe a la justicia restaurativa como "un proceso por el cual todas las partes que tienen un interés en una determinada ofensa se reúnen para resolverla colectivamente y para tratar sus implicaciones de futuro" $"$. Esta definición ha logrado un gran consenso en la doctrina, atendiendo el número de obras que la citan y la suscriben. Así, la justicia restaurativa se fundamenta en el reconocimiento de la necesidad de un contacto entre dos o más personas para resolver los problemas particulares que plantea el delito. Ella se basa en una serie de principios, entre los cuales se encuentra la implicación personal -particularmente del ofensor y la víctima, pero también de sus familias y comunidades-, la visión del problema del delito dentro de su contexto social y la flexibilidad y creatividad de su

79 Según los principales documentos supranacionales y la mayor parte de la doctrina, los principios que deben observarse son el consentimiento libre e informado de todos los intervinientes en el proceso, que puede revocarse en cualquier momento; la confidencialidad del proceso restaurativo, de manera que sólo se puede comunicar algún dato en caso de inminente delito o sólo comunicar a las autoridades el acuerdo alcanzado si consienten todos los intervinientes en el proceso restaurativo; un cierto equilibrio de poder entre las partes, que implica la libertad para debatir y llegar a soluciones sin que los participantes se vean sometidos a presiones y coacciones; la seguridad de la víctima en el proceso; la imparcialidad del mediador o facilitador y que el resultado sea adoptado libremente por las partes y sea razonable y proporcional. Vid., por todos, TAMARIT SUMALLA, J.: "La justicia restaurativa: concepto, principios, investigación y marco teórico", cit., p. 3 y ss.

80 Literalmente, "Restorative Justice is a process whereby parties with a stake in a specific offence collectively resolve how to deal with the aftermath of the offence and its implications for the future", MARSHALL, T. F.: Restorative Justice. An overview, cit., p. 5. 
práctica. La justicia restaurativa se dirige a la restauración, entendida por MARSHALL como una restauración de la víctima, del ofensor y del daño causado a la comunidad ${ }^{81}$. Así, parte de la doctrina afirma que una de las características principales del proceso restaurativo es la participación activa de las personas afectadas por el delito -las víctimas, los ofensores, sus familias y la comunidad- para la reparación de sus consecuencias, con ayuda de un tercero imparcial, llamado mediador o facilitador ${ }^{82}$.

Las normas supranacionales que se ocupan de la justicia restaurativa también parecen acoger, al menos en sus comienzos, un concepto estricto de justicia restaurativa. Así, la Resolución del Consejo Económico y Social de Naciones Unidas titulada Principios básicos sobre la utilización de programas de justicia restaurativa en materia penal de 2002, define el "proceso restitutivo" como "todo proceso en que la víctima, el delincuente $y$, cuando proceda, cualesquiera otras personas o miembros de la comunidad afectados por un delito, participen conjuntamente y de forma activa en la resolución de cuestiones derivadas del delito, por lo general con la ayuda de un facilitador ${ }^{83}$ " y define "resultado restitutivo" como aquél "acuerdo logrado como consecuencia de un proceso restitutivo. Entre los resultados restitutivos se pueden incluir respuestas y programas como la reparación, la restitución y el servicio a la comunidad, encaminados a atender a las necesidades y responsabilidades individuales y colectivas de las partes y a lograr la reintegración de la víctima y el delincuente ${ }^{84}$ ". Asimismo, Naciones Unidas se ocupa de algunos tipos de procesos, como la mediación víctima-ofensor (directa o indirecta), family group conferencing, community conferencing,

81 Ob. cit., p. 7.

82 Vid., por todos, GORDILLO SANTANA, L.F.: La justícia restaurativa..., cit., p. 57 y ss.

83 Punto 2 de los Principios Básicos sobre la utilización de los programas de justicia restaurativa en materia penal (Resolución 2002/12 del Consejo Económico y Social).

84 Punto 3 ob. ult.cit. 
sentencing cirles, peacemaking circles, entre otros ${ }^{85}$. Sobre la mediación penal, la recomendación $n^{\circ} \mathrm{R}(99)$ del Consejo de Europa, la definía como "todo proceso que permite a la víctima y al delincuente a participar activamente, si consienten libremente, a la solución de las dificultades del delito, con la ayuda de un tercero independiente (mediador)" ${ }^{\prime \prime 6}$. Esta Resolución se ha visto superada por la Recomendación CM/Rec (2018) que, como veremos, concibe a la justicia restaurativa en un sentido amplio.

Por su parte, la Unión Europea sigue también un concepto estricto de justicia restaurativa. Así, la Directiva de la Unión Europea 2012/29/UE, de 25 de octubre de 2012, define a la "justicia reparadora" en el art. 2 como "cualquier proceso que permita a la víctima y al infractor a participar activamente, si dan su consentimiento libremente para ello, en la solución de los problemas resultantes de la infracción penal, con la ayuda de un tercero imparcial".

Por lo tanto, en lo que aquí nos interesa destacar, estos documentos supranacionales conciben la justicia restaurativa como proceso en el que al menos debe participar víctima y ofensor. Siendo así, no es de extrañar que algunos autores sostengan la imposibilidad de aplicar la justicia restaurativa en los casos donde no exista una víctima identificada. Tal es el caso de Andrew von HIRSCH, Andrew ASHWORTH y Clifford SHEARING en su modelo "making amends". Tales autores entienden que el modelo de reparación se dirige a un cierto tipo de casos, aquellos en los que existe una persona identificable que es el delincuente, otra persona identificable que es la víctima, y un acto de victimización que infringe los derechos de esta última ${ }^{87}$.

85 Para una explicación de estos procesos y cómo se llevan a cabo en distintos países, vid. OFFICE ON DRUGS AND CRIME: Handbook on Restorative Justice Programmes, United Nations, New York, 2006.

86 Recommandation $\mathrm{n}^{\circ} \mathrm{R}(99)$ du Comité des Ministres aux États membres sur la médiation en matière pénale.

87 Cfr., VON HIRSH, A./ ASHWORTH, A./ SHEARING, C.: "Specifying Aims and Limits for Restorative Justice: A 'Making Amends' Model?", cit., p. 28. 
Como se podrá advertir, ello representa una gran dificultad en el ámbito de delincuencia de cuello blanco, dadas las características que hemos expuesto con anterioridad. Estos mismos autores sostienen que parece menos adecuada la utilización de la justicia restaurativa en casos donde no hay víctimas individuales, poniendo el ejemplo de la evasión fiscal, delito donde no existe ninguna persona a quien se le pueda transmitir una actitud de disculpa a través de algún tipo de acto de restitución. Apelar a la "comunidad" no aclara, según los autores, quién es la víctima en estos $\operatorname{casos}^{88}$.

\subsection{Concepto amplio de Justicia Restaurativa}

Como se acaba de observar, la necesaria concurrencia de, al menos, ofensor y víctima en un proceso dificulta la aplicación de la justicia restaurativa en gran parte de delitos. Los partidarios de un concepto amplio de justicia restaurativa flexibilizarán la idea de proceso, sostendrán que no necesariamente deberán estar implicados todos los actores que tengan un interés en el delito cometido o bien admitirán que, en una iniciativa restaurativa concreta, no necesariamente tienen que estar presentes todos los objetivos reparadores, por lo que se aceptarán como justicia restaurativa prácticas que no persigan la reparación a la víctima.

En la línea de trascender el necesario "proceso" restaurativo, se encuentra Lode WALGRAVE, quien considera que la definición de MARSHALL antes expuesta es demasiado restrictiva $^{89}$ y concibe la justicia restaurativa como algo más que un proceso, poniendo el acento en el perjuicio acusado ${ }^{90}$. Entiende que las definiciones de justicia restaurativa que hacen referencia al proceso confundirían los medios con las finalidades y limi-

88 Ob. cit. p. 28.

89 WALGRAVE, L.: "La justice restaurative (1): à la recherche d'une théorie et d'un programme", cit., p. 3.

90 Así, afirma que la reparación de los perjuicios causados es la clave para comprender la justicia restaurativa y para diferenciarla de los modelos tradicionales de justicia (Cfr. WALGRAVE, L. "La justice restaurative et les víctimes", Le Journal International de Victimologie 1(4), 2002). 
tarían los medios posibles para alcanzar la restauración ${ }^{91}$. Así, mientras la justicia restaurativa se presente sólo como un arreglo voluntario entre víctimas y delincuentes (y sus comunidades), basados en un acuerdo aceptado libremente por las partes implicadas, estará condenada a permanecer como un addendum, al margen del hueso duro de la justicia penal. Es por ello que una opción maximalista presentaría, según el autor, un nuevo paradigma a desarrollar para convertirse a largo plazo en una alternativa completa y sistemática a los sistemas punitivos y rehabilitadores ${ }^{92}$.

De este modo, WALGRAVE define la justicia restaurativa como "una óptica sobre la manera de hacer justicia, orientada prioritariamente hacia la reparación de los sufrimientos y daños causados por un delito"93. Es posiblemente como consecuencia de la concepción de justicia restaurativa centrada esencialmente en el resultado reparador lo que conduce a este autor a admitir, dentro de la misma, la posibilidad de procedimientos coactivos ${ }^{94}$ en los casos en que el ofensor sea poco cooperativo y la inclusión de ciertos tipos de sanciones, con el objetivo de dotar a la justicia restaurativa del máximo alcance posible ${ }^{95}$. En los casos donde el autor del delito no haya sido identificado, no sea posible un encuentro entre víctima y ofensor o los contactos no fi-

91 Vid., WALGRAVE, L.: "Integrating criminal justice and restorative justice”, en JOHNSTONE, G./ VAN NESS, D.N.: Handbook ... cit., p. 565.

92 WALGRAVE, L.: "La justice restaurative (1): à la recherche...", cit., p. 5-6.

93 Literalmente, "une optique sur la manière de faire justice, orientée prioritairement vers la réparation des souffrances et dommages causés par le délit", cfr. WALGRAVE, L.: "La justice restauratrice et les victimes",cit. El autor concibe la reparación de una manera amplia, que incluye todo tipo de perjuicios - materiales y físicos, psicológicos o trastornos relacionales- referidos tanto a la víctima como al ofensor y a la sociedad en su conjunto, estos últimos relativos a los sentimientos de inseguridad o la pérdida de confianza en las autoridades (ob. cit.).

94 Cfr. WALGRAVE, L.: "La justice restaurative (1): à la recherche...", cit., p. 3. Afirma este autor que un sistema judicial orientado hacia el uso de la fuerza no tiene por qué ser necesariamente un sistema punitivo, sino que puede igualmente tener un carácter restaurativo (ob. cit., p. 12).

95 Cfr., WALGRAVE, L.: "Integrating criminal justice....", cit., p. 565. 
nalicen con un acuerdo reparador ${ }^{96}$, la justicia restaurativa puede funcionar-según el mencionado autor-con la asunción de tareas de asistencia y de compensación a las víctimas por parte de la comunidad $^{97}$. En definitiva, sostiene que las medidas coactivas que buscan una reparación parcial deben incluirse igualmente en el modelo restaurativo de justicia, partiendo de que la justicia restaurativa puede penetrar en el sistema con diversas acciones y en diversos grados. Serían, a su juicio, ejemplos de acciones reparadoras la restitución, la multa, el trabajo en beneficio de un fondo para las víctimas o los trabajos en beneficio de la comunidad ${ }^{98}$.

Atendiendo a los sujetos participantes en el proceso restaurativo se encuentra la teoría de Paul McCOLD y Ted WACHTEL, quienes consideran que un programa es plenamente, principalmente o parcialmente restaurativo en función del grado en el cual las tres partes -víctima, ofensor y comunidadparticipan en él. Así, sería plenamente restaurativo cuando intervienen las tres, cosa que se produce en los procesos de conferencing con víctima o en los peacemaking circles. Principalmente restaurativos serían aquellos procesos donde intervienen dos de las tres partes implicadas. Tal es el caso de la mediación penal, los conferencing sin víctimas, las comunidades terapéuticas o los programas de apoyo a las víctimas. Finalmente, serían parcialmente restaurativas, según los autores, la victimoasistencia, la compensación o indemnización del daño, el tratamiento y sensibilización hacia la víctima, los trabajos en beneficio a la comunidad o los programas de reinserción social ${ }^{99}$.

96 Ob. ult. cit., p. 566.

97 WALGRAVE, L.: "La justice restauratrice et les víctimes", cit.

98 Cfr., WALGRAVE, L.: "Integrating criminal justice...”, cit., p. 566. En sentido similar, afirma que existen, en el arsenal de medidas disponibles por los Magistrados, sanciones verdaderamente restaurativas, CAIRO, R.: "De la reconnaissance des droits des víctimes à la justice restaurative", en FATTAH, E./ PARMENTIER, C. (Eds): Victim policies and criminal justice on the road to restorative justice. Essais in honour of Tony Peters, Leuven University Press, 2001, p. 139 y ss.

99 Crf. McCOLD, P./ WACHTEL, T.: "Restorative Justice. Theory Validation", cit., p. 110 y ss. 
Poniendo el acento en las finalidades que debe perseguir la justicia restaurativa y en cómo estas se alcanzan, Martin WRIGHT clasifica las iniciativas restaurativas como "unilaterales", "autoritarias" o "democráticas" 100 . La "justicia restaurativa unilateral" es aquella que, sin estar basada en la noción de punición, pretende beneficiar o bien al autor o bien a la víctima del delito $^{101}$. Por lo tanto, estaría orientada o bien a la rehabilitación del ofensor, a obtener indemnizaciones por parte del Estado o por parte del condenado a la víctima, a realizar trabajos de interés general e, incluso, las actividades de Victim Support. Por otra parte, la "justicia restaurativa autoritaria" se caracteriza por su paternalismo, y se centra en el resultado de reparación -concebido de forma restrictiva- que es impuesto por las autoridades, con medidas particularmente centradas en el autor del delito. Desde esta perspectiva, las víctimas únicamente son consultadas y no se encuentran implicadas en el resultado. Se trata de reparaciones impuestas, admitiendo su aplicación de manera puniti$v^{102}$. Por último, la "justicia restaurativa democrática" adopta un concepto de reparación amplio y pretende servir tanto a los intereses de la víctima como a los del autor del delito. Se pondría en práctica, en la medida de lo posible, por la comunidad y en el seno de la comunidad. Así, este tipo de justicia restaurativa autoriza a las víctimas, a los ofensores y a las personas que les apoyan para tomar decisiones sobre la reparación, no sobre la pena $^{103}$.

100 Cfr. WRIGHT, M.: “Restorative Justice: for whose benefit?” cit., p. 19-38.

101 WRIGHT sostiene que estas medidas no son del todo restaurativas porque pretenden ayudar o bien a la víctima o bien al autor (no a ambos) y porque estas medidas no vienen precedidas por una comunicación entre ellos. Ob. ult. cit.

102 Esta modalidad de justicia restaurativa queda circunscrita principalmente a delitos de poca gravedad y a aquellos cometidos por menores. Cfr. WRIGHT, M.: "Restorative justice: for whose benefit?", cit. p. 19-38.

103 De este modo, sostiene el autor que la justicia restaurativa democrática presenta una aproximación más global a la reparación, de manera que no importa solamente el resultado sinó que se incide en el proceso de comunicación entre víctima y ofensor. Cfr., WRIGHT, M.: "Restorative justice: for whose benefit?", cit. p. 19-38. 
Por otra parte, consideramos que una aproximación maximalista de la justicia restaurativa se refleja también en el último documento supranacional emanado del Consejo de Europa en 2018, el cual no se ocupa ya de la mediación penal sino del concepto más amplio de justicia restaurativa. Pese a que sigue definiendo la justicia restaurativa como un "proceso", caracterizado por la "participación activa" de las personas que han sufrido un "perjuicio" con la ayuda de un tercero imparcial (facilitador) ${ }^{104}$, entendemos que se inscribe en una concepción amplia atendiendo a diversos factores. En primer lugar, porque establece que "las prácticas que no prevean un diálogo entre las víctimas y los autores de infracciones pueden tener un carácter reparador si se adecuan a los principios fundamentales de la justicia restaurativa", aclarando además que los principios y aproximaciones restaurativas pueden también ser aplicadas en el seno del sistema de justicia penal ${ }^{105}$. En segundo lugar, cuando se ocupa de los principios fundamentales de la justicia restaurativa, afirma que éstos "pueden servir de marco para llevar a cabo reformas a mayor escala de la justicia penal"106.

Según las concepciones amplias de justicia restaurativa, parece que ésta podría ser aplicable en la delincuencia socioeconómica.

\subsection{Toma de posición}

De acuerdo con las dos tendencias conceptuales expuestas, resulta claro que la justicia restaurativa se considera mayoritariamente como complemento del sistema de justicia penal. Sin embargo, esta complementariedad puede entenderse, a mi juicio, de dos modos distintos: o bien como proceso restaurativo que es paralelo al sistema de justicia penal y que puede complementarlo si se reconocen efectos en éste; o bien como un

104 Cfr., punto 3 de la Recommandation CM/Rec(2018)8 du Comité des Ministres aux États membres relative à la justice restaurative en matière pénale.

105 Cfr. apartado II, punto 8 ob. ult. cit.

106 Cfr., apartado III, punto.14 de la Recomendación CM/Rec(2018)8. 
conjunto de principios y objetivos que pueden influir en el sistema penal en su totalidad, repensando instituciones penales desde una perspectiva restaurativa. Dependiendo de cómo se defina la justicia restaurativa, encontraremos manifestaciones de uno y otro sentido. Por lo tanto, la manera de concebir la justicia restaurativa incidirá en cómo ésta se relaciona con el sistema de justicia penal. De este modo, entiendo que los seguidores de un concepto estricto de justicia restaurativa sitúan a la misma en un espacio paralelo, pero que puede complementar al sistema penal, mientras que, aquellos que sostienen un concepto amplio de la justicia restaurativa, plantearán además cambios en las propias instituciones penales que poco tendrán que ver con el seguimiento de un proceso restaurativo.

Considero que ambas tendencias que se han identificado presentan inconvenientes, unas porque se han visto superadas por la realidad práctica actual y otras porque pretenden abarcar toda la realidad, es decir, cualquier iniciativa que esté orientada a la reinserción del ofensor o a la reparación de la víctima.

Una de las características principales de la justicia restaurativa es que la práctica siempre ha ido por delante de su elaboración teórica ${ }^{107}$. En lo que ahora interesa destacar, se observa que las concepciones estrictas que sostienen la necesaria presencia, al menos, de un ofensor y de una víctima no contemplan los avances de otros procesos restaurativos donde, en aras a alcanzar una mayor reinserción social de jóvenes delincuentes, se realizan family group conferencing sin víctimas. De hecho, en las Leyes donde se regula su práctica, no se establece la participación de la víctima como obligatoria para que el proceso restaurativo sea viable y, en la práctica de algunos programas, se constata que la participación directa de la misma es porcentualmente baja. Las experiencias de conferencing, ya consolidadas, en países como Nueva Zelanda, Irlanda del Norte y Bélgica son un buen ejemplo de ello ${ }^{108}$.

107 De esta opinión, TAMARIT SUMALLA, J.: "La justicia restaurativa: concepto, principios, investigación y marco teórico", cit., p. 4.

108 Sobre la legislación, la descripción de los programas de conferencing y los resultados de evaluación de los mismos en Nueva Zelanda, Australia, 
La segunda de las opciones expuestas en la que, con distintas matizaciones, se califican como "justicia restaurativa" indemnizaciones de carácter estatal, programas de asistencia a la víctima, e incluso sanciones penales, como multas, trabajos en beneficio de la comunidad u otras medidas institucionalizadas orientadas a la reinserción, desdibujan por completo las diferencias de la justicia restaurativa con la victimología y con el sistema de justicia penal. Así, si todo es justicia restaurativa, nada será justicia restaurativa, quedando completamente absorbida, principalmente por el sistema penal.

A mi juicio, la justicia restaurativa debe reivindicar un espacio propio y complementario al sistema de justicia penal, cosa que entiendo que se consigue manteniendo la necesaria concurrencia de un proceso donde participan las personas -físicas o jurídicas- más afectadas por el delito cometido con la ayuda de facilitadores profesionales. Entiendo que la justicia restaurativa debe superar todas las influencias que ha tenido en sus comienzos y constituir un corpus propio, pero a su vez aceptar que los objetivos que persigue también son compartidos por otras instituciones, aunque por medios distintos. Así, comparte con el sistema de justicia penal el fin de prevención general reintegradora y de prevención especial positiva (reinserción). Además, comparte con la victimología los objetivos de reparación y de asistencia a la víctima. Sólo en un espacio de complementariedad de sistemas, y desde el reconocimiento de que las vías para alcanzar los objetivos preventivos y reparadores son distintas, la justicia restaurativa puede mantener una identidad propia. Con independencia de esta reflexión, que puede ser compartida o no, en lo que sigue reflexionaremos sobre la posibilidad de aplicar la justicia restaurativa en la delincuencia socioeconómica, ya sea en un sentido estricto o amplio.

Irlanda del Norte y Bélgica, vid., GUARDIOLA LAGO, M.J./ ALBERTÍ CORTÉS, M./ CASADO CORONAS, C./ MARTINS, S./ SUSANNE, G.: ¿Es el conferencing una herramienta útil para los programas de mediación en el ámbito penal del Departamento de Justicia?, CEJFE, Barcelona, 2012, pp. 56-160. 


\section{La aplicación de la justicia restaurativa en la delincuencia de cuello blanco: posibilidades y límites}

La admisión de la justicia restaurativa en los delitos socioeconómicos no es, ni mucho menos, pacífica en la doctrina. Como hemos visto, algunos niegan su viabilidad por no tratarse de delitos que implican a un ofensor y una víctima persona física concreta $^{109}$. Sin embargo, este no ha sido el único inconveniente planteado. Otros autores, preocupados por las características del infractor socioeconómico, consideran inviable los procesos restaurativos por el elevado riesgo de manipulación del proceso por parte del mismo, afirmando, no obstante, la viabilidad de la justicia restaurativa en los casos de delincuencia corporativa ${ }^{110}$. Las herramientas tradicionales de las que dispone la justicia restaurativa también han sido, para otros autores, objeto de discusión, proponiendo en algunos casos otras soluciones más cercanas a la justicia transicional ${ }^{111}$. Tal y como apuntamos en este trabajo, las posibilidades de aplicar la justicia restaurativa en la delincuencia de cuello blanco dependen del concepto de justicia restaurativa que se maneje, pudiendo tener diferentes alcances.

Concebida la justicia restaurativa en sentido estricto, ésta no sería aplicable a la mayor parte de delitos de cuello blanco ${ }^{112}$. Quizás por ello, los autores que son más proclives a aplicar la justicia restaurativa en este ámbito no citan, por lo general, las

109 Vid. supra, VON HIRSH, A./ ASHWORTH, A./ SHEARING, C.: "Specifying Aims and Limits for Restorative Justice: A 'Making Amends' Model?", cit., p. 28.

110 Vid., CHISTE, K.B. "Retribution, Restoration, and White-Collar Crime", 31, Dalhousie, L.J. 85, 2008, p. 87 y ss.

111 En este sentido, GABBAY, D.: "Exploring the limits of the restorative justice paradigm: Restorative Justice and White-Collar Crime", quien propone desarrollar un modelo diferente inspirado en el modelo de la Comisión de la Verdad y Reconciliación sudafricana. Sostiene que agregar una intervención restaurativa a la respuesta pública del delito de cuello blanco de alto perfil no sólo es apropiado y teóricamente justificado sino también técnicamente posible y útil.

112 Vid., VON HIRSH, A./ ASHWORTH, A./ SHEARING, C.: "Specifying Aims and Limits for Restorative Justice...”, cit., p. 28. 
definiciones de la Directiva de la Unión Europea ni el documento de Naciones Unidas que la definen ${ }^{113}$, o sostienen que no es posible ofrecer un concepto de justicia restaurativa, sino que se trata de un conjunto de valores y principios que pueden aplicarse en una gran variedad de respuestas al delito ${ }^{114}$.

En mi opinión, en este tipo de delitos no es posible aplicar la mediación penal, pero sí otros procesos restaurativos, como el conferencing, -adaptado a las especificidades de este tipo de delincuencia-, o bien otros procesos reparadores que, sin necesidad de incluir a víctimas directas, puedan implicar a diversos actores sociales junto al ofensor o la persona jurídica que ha ocasionado el delito ${ }^{115}$.

113 Así, por ejemplo, LUEDKE, D.: "Progression in the age of Recession...", cit.

114 Así lo sostiene AERTSEN, I.: "Restorative justice for victims of corporate violence", en FORTI, G. (Ed.): Victims and corporations. Legal Challenges and Empirical Findings, Wolters Kluwer, CEDAM, Milano, 2018, p. 243.

115 En contra, GABBAY entiende que en los casos de delincuencia de cuello blanco en los que no exista una víctima persona física no es posible llevar a cabo estos procesos restaurativos. Argumenta que, si la justicia restaurativa debe utilizar víctimas representativas, ya contamos con el sistema de justicia penal, el cual se caracteriza por la utilización de representantes (Fiscales, Abogados...). Cfr. GABBAY, D.: "Exploring the limits...", cit., p. 463. El argumento es sugerente, especialmente en los casos en los que, como indica el autor, se utilizan a víctimas representativas. Sin embargo, considero que no resulta suficiente para negar la aplicabilidad de la justicia restaurativa en este tipo de delincuencia. Esta analogía 'de representantes' soslaya las diferencias procedimentales entre la justicia penal y la justicia restaurativa y sus distintas finalidades. Además, las diferencias entre los representantes que intervienen en un proceso penal y los que lo hacen en un proceso restaurativo son sustanciales, e impiden una equiparación. En la opción de proceso restaurativo que proponemos en este trabajo - complementario al sistema de justicia penal- se reduce al máximo la 'representación' de los implicados en el delito. Por una parte, como veremos, sostenemos la participación directa del ofensor en el proceso restaurativo (en caso de ser persona física) o de un representante legal si es persona jurídica, pero que en ningún caso realizaría las mismas funciones que un abogado en un proceso penal. Por otra parte, en el caso de la víctima difusa, se acerca al máximo la necesaria 'representación' a aquellas personas o entidades afectadas por el delito, por lo que su perspectiva será diferente a la de un Fiscal y el contenido de su participación también será distinto. Además, se contempla la participación de otros actores sociales, superando la dicotomía de acusación y defensa propia de 
Entiendo que no es posible realizar mediaciones penales atendiendo a las siguientes consideraciones: a) Ya desde el punto de vista conceptual, resulta muy difícil identificar a una víctima concreta en delitos contra bienes jurídicos supraindividuales; b) Desde el punto de vista práctico y de adecuación a los principios de justicia restaurativa, resultaría complicado respetar el equilibrio de poder entre los participantes. En este sentido, se constata en los estudios sobre delincuencia socioeconómica la gran desigualdad de información, de formación técnica y de experiencia profesional entre el ofensor y los afectados por el delito. Desde el otro lado de la balanza, en delitos donde exista un solo ofensor y un gran grupo de afectados, puede generarse la situación contraria y convertir el encuentro restaurativo en una especie de escarnio colectivo, a modo de pena infamante, contra el ofensor. Entiendo que, para que el encuentro restaurativo cumpla con las condiciones de equilibrio de poder entre los participantes, libertad para debatir y llegar a soluciones sin sometimiento a presiones ni manipulaciones, y para mantener la seguridad y evitar una revictimización, es necesaria la intervención de diversos actores sociales, con las dificultades de determinar qué es la sociedad y la elección concreta de sus miembros que veremos más adelante.

Por lo tanto, considero que el argumento de que ya se realizan procesos restaurativos sin la presencia de la víctima directa o bien utilizando víctimas representativas o sustitutas no es suficiente para soslayar las dificultades de aplicación de la justicia restaurativa en este ámbito. Así, de acuerdo con Ivo AERTSEN, se deben modificar los conceptos de delincuentes, víctimas, comunidad y daño ${ }^{116}$. Veamos algunas especificidades en la delincuencia de cuello blanco.

un proceso penal. Así, ni los objetivos y finalidades de los distintos procesos se pueden equiparar, ni son homologables los distintos sujetos, ni el papel que juegan en cada uno de los procesos puede ser el mismo. Por todo ello, entiendo que no se puede equiparar la representación de los diversos actores jurídicos en un proceso penal con las víctimas representativas en un proceso restaurativo.

116 AERTSEN, I.: "Restorative justice for victims of corporate violence", cit., p. 243. 


\subsection{Infractor}

Sobre el acusado/condenado por un delito de cuello blanco, se debe diferenciar entre los casos en los que se trata de una persona física y los supuestos donde es una persona jurídica.

En el ámbito de la persona física, ya hemos esbozado con anterioridad algunos inconvenientes en relación a características personales del infractor, señaladas por parte de la criminología. Sin embargo, no siempre estas características personales están presentes, por lo que no resulta un argumento suficiente para rechazar, en cualquier caso, la intervención de la justicia restaurativa en este ámbito delincuencial. Con todo, no debe tampoco desdeñarse que se trata de un factor de riesgo importante en este ámbito, que debe ser tenido muy en cuenta a la hora de valorar la viabilidad de un caso ${ }^{117}$. Admitiendo, pues, que en ocasiones pueden surgir dudas al respecto, no veo inconveniente en solicitar en algunos casos la colaboración de un psicólogo, que podría - previo consentimiento del ofensor-realizar una valoración previa $^{118}$.

Por lo que respecta al infractor persona jurídica (el llamado, corporate crime), es uno de los ámbitos en los que actualmente se está prestando mayor atención. Entendemos que se trata de aquellos delitos cometidos en beneficio -directo o indirecto- de la persona jurídica, ya sea a través de sus representantes legales o por aquellos con capacidad de comprometer a la persona jurídica, ya sea por sus trabajadores por defecto de organización. Como es lógico, este tipo de criminalidad puede ocasionar diferentes victimizaciones, las cuales analizaremos en el siguiente epígrafe (víctimas masa, víctimas de violencia corporativa, víctimas difusas, etc.). Pero, en lo que aquí interesa destacar, la respuesta hasta el momento dista de ser satisfactoria

117 En el mismo sentido, GABBAY, Z.D.: "Exploring the limits of the restorative justice paradigm: restorative justice and white-collar crime", cit., 457.

118 Desde una opción más incisiva, propone realizar un examen psicológico a todos los candidatos potenciales en este ámbito, LUEDKE, D.: "Progression in the Age of Recession...", cit., p. 332. 
en atención a la victimización producida y a la reparación de los daños ocasionados por el delito, como denuncia gran parte de la doctrina ${ }^{119}$. Por ello no es de extrañar que, el hecho de que el infractor sea una persona jurídica, no haya sido obstáculo para admitir la aplicación de la justicia restaurativa, sino más bien una oportunidad para que la respuesta al delito sea más completa, y que atienda a la reparación del daño social y personal ocasionado.

En la idea del win-win, tan instaurada en la justicia restaurativa, la persona jurídica también podría verse beneficiada por esta aproximación, pues al infractor le interesa mejorar la reputación y la imagen pública de la empresa ${ }^{120}$, lo que podría contribuir, si se logra, a una disminución de los efectos negativos para los trabajadores y accionistas de la empresa donde se ha cometido el delito. Destaca, en este ámbito, la labor de John BRAITHWAITE, con diferentes propuestas de aplicación de la justicia restaurativa. Entre otras, se centra en la responsabilidad penal de las entidades bancarias, y en el papel que habría podido jugar la justicia restaurativa en la crisis financiera, argumentando que la justicia restaurativa podría haberse utilizado, incluso, de manera preventiva, difundiendo una cultura empresarial entre directivos y trabajadores acorde con la legalidad cuando las prácticas ilegales o delictivas aún no se encontraban extendidas en la corporación ${ }^{121}$.

Por lo tanto, con un enfoque restaurativo, el sistema de compliance trascendería de la simple gestión de riesgos desde

119 Entre otros, NIETO MARTÍN, A.: “Empresas, víctimas...”, cit., p. 319; AERTSEN, I.: "Restorative justice for victims of corporate violence", cit., p. 240; VARONA MARTÍNEZ, G.: "Elementos victimológicos en la definición de la necesidad de pena...", cit., p. 79-80.

120 Señala esta motivación en participar en iniciativas restaurativas, entre otros, AERTSEN, I.: "Restorative justice for victims of corporate violence", cit., p. 248.

121 Vid., concretas propuestas de procesos restaurativos en BRAITHWAITE, J.: "Restorative Justice for Banks Through Negative Licensing", The British Journal of Criminology, vol. 49, Issue 4, July, 2009. 
el punto de vista objetivo, para cumplir también una función de concienciación del daño que la empresa puede ocasionar ${ }^{122}$. Así, según NIETO "la justicia restaurativa proporciona un marco teórico, metodológico y axiológico más depurado que ayudaría a corregir los defectos de la compliance ${ }^{\text {"123 }}$, defendiendo, ante ilícitos cometidos por empresas, una cooperación entre sanciones públicas y privadas, donde el enfoque sea persuasivo -en contraposición al modelo punitivo-, y con una respuesta escalonada en gravedad de la respuesta ${ }^{124}$. Así, allí donde sea necesario, el mencionado autor apuesta por el establecimiento de un sistema de "autorregulación coaccionada" en el seno de la responsabilidad de las personas jurídicas ${ }^{125}$. Desde el plano de la justicia penal, las sanciones a las empresas tendrían que priorizar aquellas que fueran restaurativas o socializadoras, proponiendo el autor algunas de ellas. En este sentido, por ejemplo, las "order to notice to victime", llevadas a cabo en EE. UU, los servicios o trabajos en beneficio de la comunidad, destinados a reparar el daño provocado por la empresa, las "multas en beneficio de la comunidad" donde se destinaría el importe de la multa a reparar el daño causado, la imposición como obligación de hacer donativos a las organizaciones o instituciones, o la intervención comunitaria $^{126}$.

Como venimos desarrollando a lo largo de este trabajo, estas medidas pueden ser adoptadas unilateralmente por la auto-

122 De esta opinión., VARONA MARTÍNEZ, G.: "Elementos victimológicos en la definición de la necesidad de pena...", cit., p. 80.

123 Cfr., NIETO MARTÍN, A.: “Autorregulación, "compliance” y justicia restaurativa”, en ARROYO JIMÉNEZ, L./ NIETO MARTÍN, A.: Autorregulación y sanciones, $2^{\mathrm{a}}$ ed., Aranzadi, Navarra, 2015, p. 122.

124 Ob.cit.

125 Donde la primera forma de coaccionar sería sancionar aquellas empresas que no dispongan de medidas de autorregulación eficaces y, la segunda obligar a la publicación de informes anuales acerca de su respeto, siendo sancionadas, incluso penalmente, si son inveraces. Cfr. NIETO MARTÍN, A.: "Autorregulación...", cit., p. 132 y ss.

126 Vid., ampliamente, dando cuenta de experiencias concretas, NIETO MARTÍN, A.: "Empresas, víctimas...", cit., p. 319 y ss. 
ridad judicial -en caso de estar previstas legalmente, aunque en algunos casos no es así- o determinarse, en contenido y destino, a través de un proceso restaurativo donde intervengan representantes de la persona jurídica y diferentes actores implicados, más cercanos al daño ocasionado. Revisadas por la autoridad judicial, entre otros aspectos, que el proceso restaurativo se haya desarrollado en las condiciones óptimas y la proporcionalidad de los acuerdos adoptados ${ }^{127}$, pueden ser tenidas en cuenta en el orden penal para valorar la sentencia finalmente impuesta o los indicios de "reinserción" del condenado. Entendemos que los efectos jurídicos no deben ser automáticos y que la verificación, por parte del sistema de justicia penal, de que se han cumplido los acuerdos adoptados es primordial.

\subsection{Víctima}

Superadas las primeras investigaciones victimológicas que se centraban en el estudio de la "pareja criminal", y que clasificaban a la víctima individual en función de su relación con el ofensor o su relación con el hecho delictivo, parte de la doctrina ha puesto de manifiesto la existencia de "víctimas colectivas". En este sentido, NEUMANN (1985), clasifica a las víctimas como individuales, familiares y colectivas, acogiendo dentro de esta última categoría a la delincuencia de cuello blanco ${ }^{128}$. Otros autores en España, como LANDROVE DÍAZ ${ }^{129}$ o MORILLAS FERNÁNDEZ ${ }^{130}$, también aluden a la "víctima colectiva" en

127 En cambio, sostiene que únicamente el control judicial debe establecerse solo en cuanto a si existe un escenario que reúna las condiciones y no en los contenidos, NIETO MARTÍN, A.: “Empresas y víctimas...” cit., p. 327.

128 Cfr., MORILLAS FERNÁNDEZ, D.L./ PATRÓ HERNÁNDEZ, R.M./ AGUILAR CÁRCELES, M: Victimología: un estudio sobre la víctima y los procesos de victimización, Dykinson, Madrid, 2011, p. 169. En esta obra se ofrece una exposición detallada de las tipologías de víctima a través de los diferentes autores.

129 Vid., LANDROVE DÍAZ, G.: La moderna victimología, Tirant lo Blanch, Valencia, 1998, p. 46-47.

130 Cfr., MORILLAS FERNÁNDEZ, D.L./ PATRÓ HERNÁNDEZ, R.M./ AGUILAR CÁRCELES, M: Victimología: un estudio sobre la víctima..., cit., p. 200. 
sus clasificaciones, poniendo como ejemplos desde delitos financieros y fraudes a los consumidores hasta victimizaciones a un colectivo de víctimas concretas. Con todo, la victimología ha prestado más atención a la víctima individual, hasta el punto de que, en la manualística que aborda la victimización por concretos delitos, rara vez se incluye un apartado específico de victimización en la delincuencia de cuello blanco.

Más allá de la categoría genérica de "víctimas colectivas", y a los efectos de idear programas específicos de justicia restaurativa para este tipo de víctimas en delitos económicos, identifico diferentes grupos de casos que pueden incluirse dentro de esta noción:

\section{Víctima persona jurídica:}

Especialmente en los delitos económicos, cabe pensar en que la víctima del delito pueda ser una entidad, pública o privada. $\mathrm{Su}$ reconocimiento jurídico es paulatino, aunque apunta en esta dirección. Así, el art. 109 bis 3 de la Ley de Enjuiciamiento Criminal española, modificada por el Estatuto de la víctima del delito, admite la posibilidad de que se inste la acción penal por parte de asociaciones de víctimas o personas jurídicas con legitimación para defender sus derechos ${ }^{131}$. En cambio, la Directiva 2012/29/UE refiere como víctima tan sólo a la persona física, de manera similar a como lo hacía su predecesora, la Decisión Marco 2001/2020/JAI ${ }^{132}$. En aplicación de esta última, la sentencia del TJUE C-205/2009, de 21 de octubre de 2010, sostuvo que "los artículos 1, letra a) y 10 de la Decisión marco deben interpretarse en el sentido de que el concepto de "víctima" no incluye a las personas jurídicas a efectos de impulsar la mediación en las

131 Considera que esta previsión, junto con la acción popular, puede tener una importancia fundamental en la defensa de los intereses de las víctimas, PLANCHADELL GALLARDO, A.: "Las víctimas en los delitos de corrupción...", cit., p. 77.

132 Sin embargo, considera que la Directiva 2012/29/UE es muy similar en la regulación de los derechos e intereses de las personas físicas y las personas jurídicas, CASABÓ ORTÍ, M.A./ CASABÓ ORTÍ, L.: "Mediación penal y la persona jurídica”, La Ley, 2059/2017, p. 8. 
causas penales a que se refiere dicho artículo 10, apartado 1". No obstante, puntualiza, "la Decisión marco ni impide ni obliga a los Estados miembros a aplicar lo en ella dispuesto también en los casos en que la víctima sea una persona jurídica". Con todo, parece justificar una prioridad en las victimizaciones personales, puesto que "el legislador de la Unión ha podido establecer de manera legítima un régimen protector en favor únicamente de las personas físicas porque estas últimas se hallan en una situación objetivamente diferente a la de las personas jurídicas debido a su mayor vulnerabilidad y a la naturaleza de los intereses que sólo pueden lesionarse en el caso de las personas físicas, como la vida y la integridad física de la víctima".

También desde el punto de vista teórico se ha prestado poca atención a la víctima persona jurídica, y la doctrina ha señalado diversos motivos, entre los que se encuentran ${ }^{133}$ : a) tradicionalmente, como hemos visto, se ha representado el delito en este ámbito como "una violación de un individuo contra otro", lo que apela a la victimización personal; b) los efectos positivos de la justicia restaurativa para la víctima también se han centrado tradicionalmente en los beneficios psicológicos o emocionales; c) se sostiene que el representante institucional en tales casos se percibe como una figura de autoridad impersonal, incapaz de transmitir al ofensor los efectos provocados por el delito tal y como lo haría una persona física que ha sufrido directamente las consecuencias del delito; d) las víctimas corporativas podrían parecer "ideológicamente desagradables", en los casos en los que son grandes y poderosas corporaciones y los ofensores son pobres y débiles; e) pueden existir dificultades en determinar quien actúa como representante de la persona jurídica y, en el caso de la designación repetida de una misma persona, es probable que sus contribuciones se vuelvan cada vez más "formuladas y rutinarias" 134 , lo que las haría mucho menos significativas para el ofensor y fomentarían una "lógica de exclusión" social, más que un enfoque reintegrativo.

133 En este sentido, vid. DIGNAN, J.: Understandig victims ... cit., p. 176.

134 Ob. cit., p. 177. 
Teniendo en cuenta los riesgos apuntados por la doctrina, lo cierto es que en la práctica ya se están llevando a cabo procesos restaurativos con víctimas corporativas. Así, por ejemplo, en Cataluña (España), y especialmente en justicia juvenil, los datos revelan que ya en el año 2008 participaron como víctimas en las mediaciones 801 personas jurídicas, frente a 1.492 víctimas personas físicas ${ }^{135}$. Ello contrasta con el ámbito de adultos, donde su representatividad es menor (en 737 casos la víctima fue una persona física y en 47 casos una persona jurídica) ${ }^{136}$. Los datos más recientes disponibles (2018) revelan que en el mismo territorio se han llevado a cabo 136 procesos restaurativos en que las partes perjudicadas o víctimas eran personas jurídicas, como cuerpos policiales, entidades, empresas, $\mathrm{u}$ organizaciones ${ }^{137}$. Cabe, por lo tanto, realizar estudios empíricos que nos ayuden a evaluar las similitudes y diferencias de la participación como víctimas de personas jurídicas respecto a las personas físicas, los riesgos y oportunidades que ofrecen este tipo de mediaciones, así como el impacto en términos de reincidencia y reparación alcanzada.

\section{Victimas masa:}

Extraigo esta expresión del concepto de estafa masa. En estos casos se produce un delito económico en el cual el perjuicio concreto ocasionado es de poca entidad, pero que afecta a un gran grupo de personas, de manera que el beneficio económico obtenido por el autor o el daño globalmente causado puede ser muy grave. Por ejemplo, publicidad fraudulenta, fraude a los consumidores, estafas informáticas, entre otros. El principal problema en estos casos, para diseñar programas restaurativos, no sólo será la identificación de las víctimas concretas sino,

135 CASANOVAS, P./ MAGRE, J./ LAUROVA, M.E. Llibre blanc de la $\mathrm{Me}$ diació a Catalunya, Generalitat de Catalunya, 2010, p. 610.

136 Ob. cit. p. 610.

137 Cfr., Programa de Justícia Restaurativa. Memòria 2018, Generalitat de Catalunya, p. 7. Disponible en http://justicia.gencat.cat/web/.content/home/ ambits/mesures_penals_alternativ/memoria2018-justicia-restaurativa.pdf. 
además, la falta de conciencia de victimización ${ }^{138}$ y el hecho de que existe una desigualdad entre la victimización concretamente sufrida y la victimización globalmente ocasionada. Ello deberá compensarse en el diseño de procesos restaurativos, por ejemplo, con la participación de organizaciones de protección de consumidores $\mathrm{u}$ organizaciones de asistencia a víctimas de estos delitos concretos, siempre y cuando su orientación sea restaurativa.

\section{Víctimas de violencia corporativa:}

Se trata de un campo de investigación que se encuentra en auge actualmente (denominado por la doctrina como corporate violence $)^{139}$. Se produce en estos casos un atentado contra un bien jurídico supraindividual (por ej. medio ambiente, delito contra la salud pública) y, al mismo tiempo, lesiones a bienes jurídicos individuales (homicidios, lesiones) ${ }^{140}$. Casos como el aceite de colza en España, el caso Eternit en Italia (por uso de amianto en construcciones), el caso Holzschutzmittel en Alemania o el caso de la Talidomida, son ejemplos de ello. Quizás la denominación no es del todo correcta, puesto que víctimas de corporaciones también podrían ser otras empresas o víctimas difusas sin un daño personal. Además, el delito no se realiza propiamente mediante medios "violentos", en el sentido de acometimiento físico. Sin embargo, tal vez el término "violencia" en la denominación ha querido representar este rasgo distintivo -aunque impreciso- de la afectación (también) a bienes jurídicos individuales.

138 Apunta la falta de conciencia de victimización, junto con las dificultades para admitir que han sido engañadas, entre otros, AERTSEN, I.: "Restorative justice form victims of corporate violence", cit., p.237.

139 Vid., ampliamente, FORTI, G. (Ed): Victims amb corporations. Legal Challenges and empirical findings, Wolters Kluwer, CEDAM, Milano, 2018.

140 Un sector de la doctrina califica como violencia corporativa los casos en los que "las corporaciones, en el curso de sus actividades legítimas, cometen delitos en los que resulta un daño para la salud, la integridad o la vida de una persona natural". Por lo tanto, es una clase de crimen corporativo, que hemos analizado con anterioridad. Vid., AERTSEN, I. "Restorative justice for victims of corporate violence", cit., p. 236. 
La justicia restaurativa puede jugar en estos casos un papel relevante desde el punto de vista de su reparación, no sólo material, sino también psicológica. Según los estudios victimológicos se sostiene que, cuando más profundo es el sentimiento de pérdida de control que sufre la víctima a consecuencia del delito, mayor es la necesidad de información; cuanto más intensa es la angustia psicológica, es mayor la necesidad de sentirse escuchado y reconocido y cuanto más fuerte es el sentimiento de vulnerabilidad resultante de la experiencia traumática del delito, mayor es la necesidad de tranquilidad y protección ${ }^{141}$. Y, en este caso, las víctimas de corporaciones se consideran altamente vulnerables, sobre todo si son víctimas de grandes empresas $^{142}$. Además, soportan un desequilibrio de poder respecto del infractor, una falta de información y una persistencia en los efectos generados por el delito, tardando en algunos casos años en manifestarse completamente, con el añadido daño psicológico que se deriva de la incertidumbre de las consecuencias ${ }^{143}$. Por la idiosincrasia propia de las consecuencias generadas por estos delitos, un proceso restaurativo puede contribuir a antender estas necesidades, especialmente de información, de escucha y de reconocimiento. Más si se tiene en cuenta que, aunque el caso sea juzgado, resulta difícil escuchar en el juicio a todas las víctimas, más allá de su necesaria declaración a efectos de prueba. Además, debe tenerse en cuenta que, en ocasiones, el proceso penal se sigue respecto del bien jurídico colectivo, y no sobre los delitos particularmente cometidos, lo cual puede excluir a las víctimas directas de su adecuada reparación. Considerado el

141 En este sentido, VISCONTI, A.: "Corporate violence: harmful consequences and victim's needs. An overview", ob. ult. cit. p. 150.

142 En este sentido, NIETO MARTÍN, A.: "Empresas, víctimas y sanciones restaurativas...", cit., p. 316, quien afirma que "la pretensión de reparación y reconocimiento es una lucha de David frente a Goliat", ya que las empresas pueden retrasar la reparación, dominan los medios de comunicación y tienen influencia en el poder político, entre otros factores.

143 Vid., más ampliamente, las características de este tipo de victimización en AERTSEN, I.: "Restorative justice for victims of corporate violence", cit., p. 238. 
gran número de víctimas que pueden verse implicadas, puede crearse en estos casos "comisiones reparadoras" que atiendan a estos objetivos específicos.

Un ejemplo que pertenece a este grupo de victimización tal y como la he definido, pero que, sin embargo, no se menciona en algunos estudios de corporate violence, son los supuestos de delitos contra los derechos de los trabajadores en los que, además del peligro colectivo al conjunto de trabajadores de una empresa, le sigue una lesión a trabajadores concretos. La desigualdad estructural existente ${ }^{144}$ y la presencia de un interés colectivo conducen a plantear que el proceso restaurativo no pueda reducirse a una mediación y que deban introducirse otros agentes en el proceso -incluso externos a la empresa- para evitar la reproducción de desigualdades. Planteamos en estos casos la participación en el proceso de personal de la inspección de trabajo.

\section{Victima difusa:}

Hasta ahora, en gran parte de los casos planteados, además de la afectación a un interés colectivo se producía la lesión de un bien jurídico personal. En los supuestos que denominamos de víctima difusa, se espiritualiza más el concepto de victimización, porque se afecta a bienes jurídicos colectivos sin producirse, a su vez, un delito contra individuos concretos, económico o personal. Subyace en este caso la idea apuntada por un sector de la victimología de que no puede haber delito sin víctima, porque detrás de la tipificación de un hecho delictivo se encuentra la protección de un bien jurídico ${ }^{145}$. Los esfuerzos en buscar referentes individuales en la mayoría de bienes jurídicos colectivos también iría en esta línea ${ }^{146}$.

144 En este sentido, GARCÍA ARÁN, M.: “Algunas bases para la justicia restaurativa...", cit., p. 2.

145 Vid. MORILLAS FERNÁNDEZ, D.L. et al.: Victimología: un estudio...., cit., p. 105.

146 En este sentido, vid., SOTO NAVARRO, S.: La protección penal de bienes colectivos en la sociedad moderna, Comares, Granada, 2003. 
A su vez, la víctima difusa podría dividirse en: a) delitos donde el atentado al bien jurídico colectivo genera un perjuicio directo -que no delictivo, pero susceptible de indemnización civil- a determinadas personas (por ejemplo, delitos urbanísticos o delitos contra el medio ambiente donde se producen daños directos) y b) delitos donde no se produce un perjuicio directo, sino indirecto y colectivo, por ejemplo, tráfico de influencias, cohecho, fraude de subvenciones, delitos contra la hacienda pública, entre otros. En estos casos el perjuicio indirecto lo sufren las empresas competidoras, las entidades que concurren en una subvención, o claramente la sociedad en su conjunto.

Esta distinción me parece importante porque, en algunos casos, se supera la identificación de la víctima no sólo con el sujeto pasivo del delito sino, incluso, con el perjudicado. Nótese que los daños indirectos no son susceptibles de indemnización civil ex delicto. También supera el concepto de víctima previsto en el art. 2 de la Directiva 2012/29/UE y del art. 2 de la Ley 4/2015 de 27 de abril, del Estatuto de la víctima del delito.

Llegados a este punto, cabe reflexionar sobre si un daño no reconocido jurídicamente debe incluirse en una categoría de victimización y si es posible que estas víctimas difusas estén representadas como parte de un proceso restaurativo. Respecto a la primera cuestión, considero que puede responderse afirmativamente teniendo en cuenta diversos argumentos: a) desde un origen, el concepto de víctima ha sido más amplio y distinto que el de sujeto pasivo de un delito; b) Resulta adecuado en atención a sus fines: tratándose de una victimización indirecta consecuencia de un hecho delictivo, la reparación -siempre voluntaria- no sólo puede favorecer a la reparación social, sino que además puede ser un indicio favorable de reinserción social o puede revelar una menor necesidad de pena si ésta se produce. Además, puede tener un efecto preventivo general integrador. Sobre la posibilidad de que estas víctimas difusas estén representadas en un proceso restaurativo, cabe recordar que, además del ofensor y la víctima del delito, existe un tercer actor, que es la comunidad. En los casos de un perjuicio indirecto, la víctima 
difusa se diluiría con la comunidad, lo cual no significa que no siga siendo restaurativo un proceso en el que se implica al ofensor y a representantes del daño indirecto, con las dificultades de concreción que a continuación analizaremos.

Sin embargo, no se oculta la gran dificultad de evaluar quiénes son las víctimas de un concreto delito socioeconómico y cuál es la naturaleza del daño ocasionado, teniendo en cuenta además que el número de ellas puede ser considerable. Dada la idiosincrasia propia de estos delitos, la victimización colectiva sufrida y el tipo de daños que se pretende reparar con una iniciativa restaurativa, entendemos que el principio de confidencialidad debería ser adaptado a este tipo de delincuencia. Obviamente, para que el proceso restaurativo mantenga su operatividad, el contenido de aquello que se debate debería permanecer en reserva. No obstante, tanto el proceso de selección de los diversos actores que participarán en el proceso ${ }^{147}$ como el contenido del acuerdo adoptado, deberán ser públicos. En el primer caso, no sólo como mecanismo para identificar e informar a los posibles afectados, sino también como garantía de transparencia en procesos que pretenden coadyuvar a una respuesta más global a un delito que es de naturaleza colectiva. Como es lógico, no toda persona o entidad que se presente deberá ser tenida en cuenta para participar, sino que deberá ser valorada su participación de acuerdo con los principios que le son propios a la justicia restaurativa y las finalidades que ésta persigue (fundamentalmente de reparación a las víctimas y a la sociedad y de reinserción del infractor). En definitiva, los participantes deberán tener un enfoque restaurativo en el manejo del caso. En este punto cabe advertir sobre algunas experiencias que han puesto de manifiesto los riesgos de introducir participantes con una óptica poco restaurativa en estos procesos ${ }^{148}$, cuestión que abordamos a continuación

147 En el mismo sentido, GARCÍA ARÁN, M.: “Algunas bases para la justicia restaurativa en la delincuencia socieoeconómica”, cit. p.7, quien también propone algunos criterios de selección de la víctima difusa.

148 Así se puso de manifiesto en Canadá, donde la justicia restaurativa guarda mucha relación con las prácticas aborígenes. Así, la “Aboriginal Women’s 
en relación con el concepto de comunidad. La naturaleza del daño que se pretende reparar, apuntaría en la misma dirección de dar publicidad del acuerdo adoptado. Si se pretende reparar a la sociedad, la comunicación del contenido de los acuerdos alcanzados en el proceso restaurativo debería ser superior al que en estos momentos se otorga, pues en la actualidad únicamente se comunica a la autoridad judicial que conoce el caso. Una reparación social conduce incluso a plantear su difusión por parte de los medios de comunicación, aun cuando no desconocemos el factor de exposición a la crítica, en una sociedad plural.

\subsection{Comunidad}

La comunidad es el tercer actor, junto con el ofensor y la víctima, que participa en un proceso restaurativo y a la cual se le atribuyen diversos roles ${ }^{149}$, de manera que se la considera tanto medio como fin $^{150}$ :

Por un lado, constituye la parte afectada o perjudicada por el hecho delictivo, en la medida en que el delito ha producido una alteración de los valores y normas de convivencia. Si ello se expresa así en la doctrina restaurativa, mucho más en los delitos que nos ocupan, ya que la protección de intereses colectivos apela a la comunidad como uno de los principales afectados por

Action Network" (AWAM) se hizo eco de que un gran número de mujeres advirtieron sobre el peligro de aceptar alegremente la "colectividad" como benéfica para la sociedad, manifestando su preocupación sobre la posibilidad de que la justicia restaurativa repita un gran número de desigualdades del proceso acusatorio. Vid., COOLEY, D.: "La justice réparatrice au Canada: quelques enseignements", Communication faite dans le cadre du colloque Pratical Approaches to Appropriate Dispute Resolution, Vancouver (C.B), Commision du Droit Canada, 2002.

149 Vid., más ampliamente, entre otros, UNITED NATIONS. OFFICE ON DRUGS AND CRIME: Manual sobre programas de justicia restaurativa, Nueva York, 2006. ZEHR, H. Changing lenses..., cit.; ZEHR, H./MIKA, H.: "Fundamental Concepts of Restorative Justice", en McLAUGHLIN, E./ FERGUSSON, R./ HUGES, G./ WESTMARLAND, L. (Eds): Restorative justice: Critical issues, London, Sage Publications, 2003.

150 WALGRAVE, L.: Restorative justice, self-interest and responsible citizenship, Cullompton, Willan Publishing, 2008. 
el delito. Además, en los casos sobre todo de víctimas difusas, se debe aceptar que el concepto de víctima queda diluido en el de comunidad, por mucho que se intente implicar a las personas más directamente afectadas por el delito.

Por otro lado, la función que cumple la comunidad en los procesos restaurativos es apoyar a la víctima y al ofensor y facilitar la superación del delito. Desde esta perspectiva, la comunidad se hace responsable del bienestar de sus miembros y de las condiciones y estructuras sociales que provocan el delito, a la vez que ofrece recursos para la reinserción del infractor y la recuperación de la víctima.

Ahora bien, ¿qué se entiende por comunidad? La respuesta es sumamente compleja, lo que provoca que el término "comunidad" haya sido descrito por la doctrina de forma ambigua y que raramente se defina ${ }^{151}$. Una de las mayores críticas vertidas respecto a la noción de "comunidad" es que se presupone una cosa que no existe, pues no contamos con comunidades homogéneas ${ }^{152}$, ni mucho menos restaurativas en algunos casos.

En cuanto a la falta de homogeneidad, resulta evidente que la definición del término "comunidad" depende de las diferentes culturas y sociedades, señalándose diferencias entre los países de influencia anglófona respecto de los países de la Europa continental. En esta línea, por lo que se refiere a la Europa continental, se arguye que la dificultad en determinar el sentido de la comunidad no sólo radica en la fragmentación social y el individualismo característico de nuestras sociedades, sino también porque en "Europa el discurso sobre la comunidad es mantenido por el Estado y por las instituciones para promover la ciudadanía y la solidaridad, mientras que en la cultura anglosajona la comunidad es la base de una legitimidad política muy

151 En este sentido, GUARDIOLA, M.J./ ALBERTÍ, M./CASADO, C./ SUSANNE, G.: "Conferencing: origen, transferència y adaptación", en TAMARIT SUMALLA, J. (Coord): La justicia restaurativa..., cit., p. 240. 152 Ob. cit., p. 240. 
diferenciada de la del Estado"153. Quizás no sea una coincidencia que, los procesos restaurativos donde se implica a la comunidad, hayan tenido una mayor aplicación en estos últimos.

Respecto a la segunda cuestión, se debe tener en cuenta que la sociedad es muy compleja y desigual. De modo que resultaría romántico, e incluso naif, presuponer que lo que llamamos comunidad pueda tener una orientación restaurativa per se, advirtiéndose tanto desde el punto de vista teórico como práctico, de que hay comunidades que pueden ser puntitivas ${ }^{154}$. A ello se añade una complejidad en el tipo de delitos que nos ocupa. Así como existe un cierto consenso respecto a condenar un asesinato, una violación o un robo, no resulta así, en ocasiones, en la delincuencia de cuello blanco. Las reacciones sociales pueden ir desde la admiración de quien se ha saltado las reglas y ha conseguido el éxito, hasta quienes la indignación les empuja a sostener la conveniencia de un castigo ejemplarizante.

Advertidos estos riesgos, la comunidad entiendo que no debe ser considerada en abstracto, sino del entorno más cercano del acusado o condenado por un delito de cuello blanco y los afectados por el delito. Siempre y cuando, insisto, tengan éstos una orientación restaurativa, para lo cual será necesario fijar criterios que lo determinen.

Dada la idiosincrasia propia de los delitos socioeconómicos, y las distintas percepciones y reacciones que existen ante este delito, el resultado buscado quizás no sea sólo restaurar los lazos sociales o empresariales fracturados por la comisión de un delito sino, allí donde sea necesario, transformar una realidad en la que, en ocasiones, no existe una suficiente cultura de

153 MARTÍN, J./ CANO, F./DAPENA, P. “Justícia reparadora: mediació penal per adults i juvenil”, en CASANOVAS, P./ MAGRE, J./ LAUROBA, M.E. (Dirs).: Llibre Blanc de Mediació a Catalunya..., cit., p. 592.

154 Así, se afirma que las colectividades son multidimensionales y sus límites son muy flexibles de manera que, según el punto de referencia utilizado podrían ser democráticas o represivas, dinámicas, enriquecedoras o restrictivas, o todo a la vez, COOLEY, D.: "La justice réparatrice au Canada: quelques enseignements", cit. 
cumplimiento. Ello puede favorecer la reinserción, a la vez que mejorar la reincidencia, pues puede disminuir de cara al futuro la anomia, tan característica en este tipo de delincuencia.

\subsection{Daño y reparación}

Al hilo de las diferentes formas de victimización colectiva, ya se han apuntado los daños que puede generar la delincuencia socioeconómica. Algunos de ellos pueden ser de gran impacto, llegando incluso a ser mayores que el causado por un delito contra un bien jurídico individual, que podría parecer más grave $a b$ initio $^{155}$.

La reparación del daño puede realizarse o bien incluyendo en el sistema de justicia penal sanciones propiamente reparadoras o bien llevando a cabo procesos restaurativos. En el primer caso, existen experiencias en Australia para responder a los delitos contra el medio ambiente, donde se combinan sanciones con elementos reparadores. Las sentencias pueden incluir, desde una obligación para la empresa responsable de publicitar el delito y sus consecuencias hasta llevar a cabo proyectos específicos para la restauración o la mejora del medio ambiente $u$ organizar cursos de capacitación para sus empleados ${ }^{156}$.

El hecho de que se trate de delitos de peligro, o contra bienes jurídicos colectivos, o sobre víctimas difusas, no es obstáculo para considerar que se produce también un daño, susceptible de reparación. El carácter universal (o principio de universalidad) en la reparación, como señala Josep M. TAMARIT, permite aceptar formas de reparación social y simbólica, focalizando la misma en la dimensión inmaterial de la reparación. Ello requeriría, según el autor, una modificación de los criterios

155 Destaca que, aunque las víctimas de delitos corporativos no susciten tantas simpatías como la víctima de delitos violentos, violencia de género o abusos sexuales, son víctimas altamente vulnerables, sobre todo cuando se trata de delitos cometidos por grandes corporaciones, NIETO MARTÍN, A.: "Empresas, víctimas...”, cit., p. 316.

$156 \mathrm{Da}$ cuenta de estas iniciativas, AERTSEN, I .: "Restorative justice for victims of corporate violence", cit., p. 252. 
jurisprudenciales en cuanto a la apreciación de la atenuante de reparación del daño ${ }^{157}$. Desde el plano normativo, resulta de interés el Código penal canadiense, donde explícitamente se menciona el aseguramiento de la reparación a la comunidad como uno de los objetivos de la determinación de la pena, junto con otras iniciativas de prevención del delito (art. 718 ap. e) du Code Criminel) ${ }^{158}$.

Uno de los daños inmateriales que se suelen producir en esta clase de delitos es la pérdida de confianza de la ciudadanía en determinadas instituciones o empresas. Me refiero al daño reputacional, que puede sufrir no sólo el ofensor, sino también los trabajadores de la empresa y, asimismo, todas aquellas entidades que se encuentran en el mismo sector de actividad o relacionadas con ella indirectamente ${ }^{159}$. El sistema de justicia penal no resulta un contexto adecuado para reparar este tipo de perjuicios, ni es uno de sus objetivos. Sin embargo, puede ser complementado por la justicia restaurativa y ambas reacciones no son incompatibles.

En esta línea, propongo introducir en los procesos de conferencing, cuando sea conveniente, a empresarios del sector que observen las normas ${ }^{160}$, los cuales tendrían la misma fun-

157 Cfr. TAMARIT SUMALLA, J.M.: "La difícil asunción de la reparación penal por la jurisprudencia española”, cit., p. 15 y 16.

158 Textualmente, "Le prononcé des peines a pour objectif essentiel de protéger la Société et de contribuer, parallèlement a d'autres initiatives de prévention du crime, au respect de la loi et au maintien d'une Société juste, paisible et sûre par l'infliction de sanctions justes visant un ou plusieurs des objectifs suivants: e) assurer la réparation des torts causés aux victimes ou à la collectivité".

159 Sostiene que los procesos de justicia restaurativa también pueden ofrecer una oportunidad para restaurar la confianza pública en los negocios, AERTSEN, I.: "Restorative Justice for victims of corporate violence", cit., p. 250.

160 En el ámbito de la violencia corporativa, sostiene que pueden llevarse a cabo procesos restaurativos con representantes de la comunidad cercana (profesional o social) del delincuente e incluir también a víctimas internas, como empleadas y sus familias, AERTSEN, I.: "Restorative justice for victims of corporate violence", cit., p. 248. 
ción que, en la delincuencia juvenil, posee la familia del ofensor. Por una parte, estos empresarios pueden contribuir a aclarar las normas a quien ha cometido el delito, manifestando el desvalor sobre el hecho cometido ${ }^{161}$. Por otra parte, ellos también se encuentran afectados por el delito, pues se ha podido ver perjudicada la credibilidad y confianza de todo el sector empresarial o económico. Además, son los que, en definitiva, pueden contribuir a la "reintegración" de la empresa en el sector correspondiente.

Así, la justicia restaurativa puede hacer más hincapié en la concienciación sobre el daño producido ${ }^{162}$ y en la restauración de la confianza pública en los negocios o en las instituciones ${ }^{163}$. No obstante, para que ello pueda ser una realidad, es necesaria una apuesta decidida por parte de la Administración pública, a través de modificaciones legislativas, asignación presupuestaria, formación de los mediadores y del personal de la administración de justicia, creación de programas piloto evaluables científicamente y, desde luego, un distanciamiento del populismo punitivo que impera en nuestros tiempos.

\section{Bibliografía citada}

AERTSEN, I.:

"La médiation victime délinquant en cas d'infraction grave", en AA.VV: Politique pénale en Europe, Council of Europe Publishing, 2005.

"Restorative justice for victims of corporate violence", en FORTI, G. (Ed.): Victims and corporations. Legal

161 Especialmente en el ámbito de la delincuencia de cuello blanco, diversos estudios señalan la gran relevancia de factores como la pérdida de respeto y la censura social como inhibidores de la conducta delictiva, y que tendrían un peso superior al balance racional de coste-beneficio que puede reportar la comisión de un delito (GABBAY, Z.D.: "Exploring the limits...", p. 450).

162 De esta opinión, VARONA MARTÍNEZ, G.: "Elementos victimológicos en la definición...", cit., p. 80.

163 Así lo sostiene AERTSEN, I.: "Restorative justice for victims...", cit., p. 250. 
Challenges and Empirical Findings, Wolters Kluwer, CEDAM, Milano, 2018.

AERTSEN, I./ MACKAY, R./ PELIKAN, C/ WILLEMSENS, J./ WRIGHT, M.: Renouer les liens sociaux. Médiation et justice en Europe, Editions du Conseil de l'Europe, Cedex, Strasbourg, 2004

ALASTUEY DOBÓN, C.: La reparación a la víctima en el marco de las sanciones penales, Tirant lo Blanch, Valencia, 2000

ARRIBAS LÓPEZ, E. “¿Reeducación y reinserción social del delincuente de cuello blanco?", Diario La Ley, núm. 8464, 327/2015, de 22 de enero de 2015.

BAUCELLS LLADÓS, J.: "Sistema de penas para el delincuente económico", Cuadernos de Política Criminal, n¹07, 2012.

BRAITHWAITE, J:

Crime, Shame and Reintegration, University Press, Cambridge, 1989.

"Restorative Justice for Banks Through Negative Licensing”, The British Journal of Criminology, vol. 49, Issue 4, July, 2009. https://doi.org/10.1093/bjc/azp038

CAIRO, R.: "De la reconnaissance des droits des victimes à la justice restaurative", en FATTAH, E./ PARMENTIER, C. (Eds): Victim policies and criminal justice on the road to restorative justice. Essais in honour of Tony Peters, Leuven University Press, 2001.

CASABÓ ORTÍ, M.A./ CASABÓ ORTÍ, M.L.: "Mediación penal y la persona jurídica", La Ley, 2059/2017.

CASANOVAS, P./ MAGRE, J./ LAUROVA, M.E. Llibre blanc de la Mediació a Catalunya, Generalitat de Catalunya, 2010.

CHISTE, K.B. "Retribution, Restoration, and White-Collar Crime", 31, Dalhousie, L.J. 85, 2008.

CHRISTIE, N.: "Conflicts as Property", en JOHNSTONE, G. (Ed): A Restorative Justice Reader. Text, sources, context, Willan Publishing, 2003. 
COOLEY, D.: "La justice réparatrice au Canada: quelques enseignements", Communication faite dans le cadre du colloque Pratical Approaches to Appropriate Dispute Resolution, Vancouver (C.B), Commision du Droit Canada, 2002.

DE VICENTE MARTÍNEZ, R.: "Las sanciones penales en el ámbito de la delincuencia económica", Estudios de Criminología II. Ediciones de la Universidad de CastillaLa Mancha (Estudios 52), Cuenca, 1999.

DIGNAN, J., Understanding victims and restorative justice, Open University Press, McGraw-Hill, 2005.

EDELHERTH, H.: The nature, impact, and prosecution of white-collar crime, National Institute of Law Enforcement and criminal Justice, 1970.

FORTI, G. (Ed): Victims and corporations. Legal Challenges and empirical findings, Wolters Kluwer, CEDAM, Milano, 2018.

GABBAY, Z.D.: "Exploring the limits of the restorative justice paradigm: restorative justice and white-collar crime", Journal of Conflict Resolution, vol. 8.2, 2007.

GARCÍA ARÁN, M.: "Algunas bases para la justicia restaurativa en la delincuencia socioeconómica", Libro Homenaje a Diego-Manuel Luzón Peña (en prensa).

GARCÍA-PABLOS DE MOLINA, A.: Tratado de Criminología, $3^{\text {a }}$ ed., Tirant lo Blanch, Valencia, 2003.

GORDILLO SANTANA, L.F.: La justicia restaurativa y la mediación penal, Iustel, Madrid, 2007.

GUARDIOLA LAGO, M.J.: "Desarrollo y aplicaciones de la justicia restaurativa en prisión", en TAMARIT SUMALLA, J. (Coord): La justicia restaurativa, desarrollo y aplicaciones, Comares, Granada, 2012.

GUARDIOLA LAGO, M.J./ ALBERTÍ CORTÉS, M./ CASADO CORONAS, C./ MARTINS, S./ SUSANNE, G.: ¿Es el conferencing una herramienta útil para los programas de mediación en el ámbito penal del Departamento de Justicia?, CEJFE, Barcelona, 2012. 
GUARDIOLA, M.J./ ALBERTÍ, M./CASADO, C./ SUSANNE, G.: "Conferencing: origen, transferencia y adaptación", en TAMARIT SUMALLA, J. (Coord): La justicia restaurativa, desarrollo y aplicaciones, Comares, Granada, 2012.

KELLENS, G.: Punir. Pénologie et droit des sanctions pénales, Éditions Juridiques de l'Université de Liège, Liège, 2000.

LANDROVE DÍAZ, G.: La moderna victimología, Tirant lo Blanch, Valencia, 1998.

LASCURÁIN SÁNCHEZ, J.A./ GASCÓN INCHAUSTI, F.: "¿Por qué se conforman los inocentes?, Indret, 3/2018.

LUEDTKE, D.: "Progression in the Age of Recession: Restorative Justice and White-Collar Crime in Post-Recession America", Brooklyn Journal of Corporate Financial and Commercial Law, vol. 8, Issue 1, 2014.

MARSHALL, T. F.: Restorative Justice. An overview, Report by the Home Office Research Development and Statistics Directorate, 1999.

MARTÍNEZ-BUJAN PÉREZ, C.: Derecho penal en la empresa. Parte general, $5^{\mathrm{a}}$ ed., Tirant lo Blanch, Valencia, 2016.

McCOLD, P./ WACHTEL, T.: "Restorative Justice. Theory Validation", en WEITEKAMP / KERNER (Eds): Restorative Justice: Theoretical Foundations, Willan Publishing, Devon, 2002.

MORILLAS CUEVA, D.L./ PATRÓ HERNÁNDEZ, R.M./ AGUILAR CÁRCELES, M: Victimología: un estudio sobre la víctima y los procesos de victimización, Dykinson, Madrid, 2011.

MORÓN LERMA, E. "El perfil criminológico del delincuente económico", en GARCÍA ARÁN, M.: La delincuencia económica. Prevenir y sancionar, Tirant lo Blanch, Valencia, 2014.

NIETO MARTÍN, A.:

“Autorregulación, "compliance" y justicia restaurativa", en ARROYO JIMÉNEZ, L./ NIETO MARTÍN, A.: Autorregulación y sanciones, $2^{\mathrm{a} e d}$., Aranzadi, Navarra, 2015 
“Empresas, víctimas y sanciones restaurativas: ¿Cómo configurar un sistema de sanciones para personas jurídicas pensando en sus víctimas?", en HOYOS SANCHO, M. La víctima del delito y las últimas reformas penales, Aranzadi, Navarra, 2017.

PETERS, T. "Victimisation, médiation et pratiques vers la réparation", en CARIO, R./ SALAS, D.: Oeuvre de justice et victimes, Vol. 1, L'Harmattan, Sciences Criminelles, 2001.

PLANCHADELL GALLARDO, A.: "Las víctimas en los delitos de corrupción (panorama desde las perspectivas alemana y española), Estudios Penales y Criminológicos, vol. XXXVI, 2016.

REBOLLO VARGAS, R./ CASAS HERVILLA, J.: "El proceso penal y la investigación de la delincuencia económica", en GARCÍA ARÁN, M. (Dir): La delincuencia económica. Prevenir y sancionar, Tirant lo Blanch, Valencia, 2014.

REDONDO ILLESCAS, S./ GARRIDO GENOVÉS, V.: Principios de Criminología, $4^{\mathrm{a}}$ ed., Tirant lo Blanch, Valencia, 2013.

SCHÜNEMANN, B.: "La punibilidad de las persones jurídicas desde la perspectiva europea", en Hacia un Derecho penal económico europeo, Jornadas en homenaje al Prof. Klaus Tiedemann, BOE, 1995.

SERRANO MAÍlLO, A.: "El (sesgado) uso de los delitos de cuello blanco en los paradigmas antiempíricos", Revista de Derecho Penal y Criminología, nº 14, 2004.

SOTO NAVARRO, S.: La protección penal de bienes colectivos en la sociedad moderna, Comares, Granada, 2003.

SUTHERLAND, E.H. El delito de cuello blanco, (trad. Rosa del Olmo), Ed. La Piqueta, 1993.

TAMARIT SUMALLA, J.M.

_L La reparació a la víctima en el Dret penal. Estudi i crítica de les noves tendències político-criminals, Justícia i Societat, núm. 11, 1993 
“La justicia reparadora y su articulación con el sistema penal" en TAMARIT SUMALLA, J.M./ VILLACAMPA ESTIARTE, C.: Victimología, justicia penal y justicia reparadora, Grupo Editorial Ibáñez, Colombia, 2006.

"La difícil asunción de la reparación penal por la jurisprudencia española", Revista General de Derecho Penal, Iustel, núm. 7, 2007.

"La justicia restaurativa: concepto, principios, investigación y marco teórico", en TAMARIT SUMALLA, J.M. La justicia restaurativa: desarrollo y aplicaciones, Comares, Granada, 2012.

"La articulación de la justicia restaurativa con el sistema de justicia penal", en TAMARIT SUMALLA, J.M. $L a$ justicia restaurativa: desarrollo y aplicaciones, Comares, Granada, 2012.

UMBREIT, M.S./ VOS, B./ COATES, R.B./ ARMOUR, M.P.: "Victims of severe violence in mediated dialogue with offender: the impact of the first multisite study in the US", International Review of Victimology, vol. 13, 2006. https://doi.org/10.1177/026975800601300102

UNITED NATIONS. OFFICE ON DRUGS AND CRIME: Manual sobre programas de justicia restaurativa, Nueva York, 2006.

VARONA MARTÍNEZ, G.:

L La mediación reparadora como estrategia de control social. Una perspectiva criminológica, Comares, Granada, 1998.

“Elementos victimológicos en la definición de la necesidad de pena. Aportaciones críticas desde la justicia restaurativa", en JUANATEY DORADO, C./ SÁNCHEZMORALEDA VILCHES, N.: Derechos del condenado y necesidad de pena, Aranzadi, Navarra, 2018.

VISCONTI, A.: "Corporate violence: harmful consequences and victim's needs. An overview", en FORTI, G. (Ed): Victims and corporations. Legal Challenges and Empirical Findings, Wolter Kluwer, CEDAM, Milano, 2018. 
VON HIRSH, A./ ASHWORTH, A./ SHEARING, C.: "Specifying Aims and Limits for Restorative Justice: A 'Making Amends' Model?", en AA.VV: Restorative Justice and Criminal Justice. Competing or Reconcilable Paradigms?, Hart Publishing, Oxford and Portland, 2003. https://doi.org/10.2139/ssrn.2799216

WALGRAVE, L.:

"La justice restaurative (1): à la recherche d'une théorie et d'un programme", Criminologie, vol. 32, $\mathrm{n}^{\circ} 1,1999$.

“La justice restaurative et les víctimes", Le Journal International de Victimologie 1(4), 2002.

"Integrating criminal justice and restorative justice", en JOHNSTONE, G./ VAN NESS, D.N.: Handbook of Restorative Justice, Willan Publishing, 2007.

Restorative justice, self-interest and responsible citizenship, Cullompton, Willan Publishing, 2008.

WRIGHT, M.: "Restorative Justice: for whose benefit?" en EUROFORUMRJ, Victim-offender mediation in Europe. Making Restorative Justice Work. Leuven University Press, 2000.

ZEHR, H.:

Changing lenses: a new focus for Crime and Justice, Scottsdale, PA, Herald Press, 1990;

"Retributive Justice, Restorative Justice", en JOHNSTONE, G. (Ed).: A Restorative Justice Reader. Text, sources, context, Willan Publishing, $1^{\text {a }}$ ed., 2003.

ZEHR, H./MIKA, H.: "Fundamental Concepts of Restorative Justice", en McLAUGHLIN, E./ FERGUSSON, R./ HUGES, G./ WESTMARLAND, L. (Eds): Restorative justice: Critical issues, London, Sage Publications, 2003.

ZÚÑIGA RODRÍGUEZ, L.: "Culpables, millonarios e impunes: el difícil tratamiento del derecho penal del delito de cuello blanco", IUS, núm. 35, 2015. https://doi.org/10.35487/ rius.v9i35.2015.110 